\title{
CRÓNICA DE JURISPRUDENCIA DEL TRIBUNAL DE JUSTICIA DE LA UNIÓN EUROPEA MAYO-AGOSTO 2021
}

\author{
FERNANDO CASTILLO DE LA TORRE \\ fernando.castillo-de-la-torre@ec.europa.eu
}

PETRA NEMECKOVA ${ }^{1}$

petra.nemeckova@ec.europa.eu

I. INSTITUCIONES Y PRINCIPIOS FUNDAMENTALES. II. CONTENCIOSO. III. CIUDADANIIA, LIBRE CIRCULACIÓN Y MERCADO INTERIOR. IV. DERECHO SOCIAL. V. DERECHO DE LA ENERGÍA. VI. APROXIMACIÓN DE LEGISLACIONES. VII. JUSTICIA, LIBERTAD Y SEGURIDAD. VIII. RELACIONES EXTERIORES.

1 Servicio Jurídico de la Comisión Europea. 


\section{INSTITUCIONES Y PRINCIPIOS FUNDAMENTALES}

La legislación polaca sobre el régimen disciplinario de los jueces es contraria al derecho de la Unión, puesto que el requisito de independencia exige que dicho régimen presente las garantías necesarias para evitar todo riesgo de control político del contenido de las resoluciones judiciales (Sentencia de 15 de julio de 2021, Comisión/Polonia, C-791/19, EU:C:2021:596).

En 2017, Polonia aprobó un nuevo régimen disciplinario relativo a los jueces del Sąd Najwyższy (Tribunal Supremo, Polonia) y de los tribunales ordinarios. En el marco de esa reforma legislativa, se creó en el Tribunal Supremo una nueva sala, la Izba Dyscyplinarna («Sala Disciplinaria»). En particular, se atribuyeron a la Sala Disciplinaria los asuntos disciplinarios relativos a los jueces del Tribunal Supremo y, en apelación, los relativos a los jueces de los tribunales ordinarios. La Comisión entendía que Polonia había incumplido las obligaciones que le incumben en virtud del art. 19TUE, apdo. 1, párr. segundo, que consagra la obligación de los Estados miembros de establecer las vías de recurso necesarias para garantizar la tutela judicial efectiva en los ámbitos cubiertos por el derecho de la Unión, y del art. 267 TFUE, párrs. segundo y tercero (que establece la facultad — párr. segundo-, para determinados órganos jurisdiccionales, y la obligación — párr. tercero-, para otros, de plantear una remisión prejudicial).

El Tribunal de Justicia, en Gran Sala, estimó el recurso por incumplimiento interpuesto por la Comisión. Por una parte, el Tribunal de Justicia declara que este nuevo régimen disciplinario de los jueces menoscaba su independencia. Por otra parte, dicho régimen no permite a los jueces afectados cumplir, con plena independencia, las obligaciones que se les imponen en el marco del mecanismo de remisión prejudicial.

En primer término, el Tribunal de Justicia declara que Polonia ha incumplido las obligaciones que le incumben, en virtud del art. 19 TUE, apdo. 1, párr. segundo, de establecer las vías de recurso necesarias para garantizar la tutela judicial efectiva en los ámbitos cubiertos por el derecho de la Unión. El Tribunal recuerda que para garantizar que los órganos que puedan tener que resolver sobre cuestiones relacionadas con la aplicación y la interpretación del derecho de la Unión puedan garantizar tal tutela judicial efectiva, resulta primordial preservar su independencia, como así lo confirma el art. 47, párr. segundo, de la Carta, precepto que, entre las exigencias vinculadas al derecho fundamental a la tutela judicial efectiva, menciona el acceso a un juez «independiente». Esta exigencia de independencia de los tribunales, inherente a la función jurisdiccional, está integrada en el contenido esencial del derecho 
a la tutela judicial efectiva y del derecho fundamental a un proceso equitativo, que reviste una importancia capital como garante de la protección del conjunto de los derechos que el derecho de la Unión confiere a los justiciables y de la salvaguarda de los valores comunes de los Estados miembros proclamados en el art. 2 TUE, en particular el valor del Estado de Derecho.

Con arreglo a reiterada jurisprudencia del Tribunal de Justicia, las garantías de independencia e imparcialidad exigidas por el derecho de la Unión postulan la existencia de normas, especialmente en lo referente a la composición del órgano jurisdiccional, así como al nombramiento, a la duración del mandato y a las causas de inhibición, recusación y cese de sus miembros, que permitan excluir toda duda legítima en el ánimo de los justiciables en lo que respecta a la impermeabilidad de dicho órgano frente a elementos externos y en lo que respecta a la neutralidad de este ante los intereses en litigio. A este respecto, resulta importante que los jueces se encuentren protegidos frente a intervenciones $\mathrm{o}$ a presiones externas que puedan amenazar su independencia. Las reglas aplicables al estatuto de los jueces y al ejercicio de sus funciones deben permitir, en particular, excluir no solo cualquier influencia directa, en forma de instrucciones, sino también las formas de influencia más indirecta que pudieran orientar las decisiones de los jueces de que se trate, y evitar de este modo una falta de apariencia de independencia o de imparcialidad de esos jueces que pudiera menoscabar la confianza que la Administración de Justicia debe inspirar en los justiciables en una sociedad democrática y un Estado de Derecho.

En lo referente, más concretamente, a las normas que rigen el régimen disciplinario aplicable a los jueces, la exigencia de independencia derivada del derecho de la Unión y, en particular, del art. 19 TUE, apdo. 1, párr. segundo, obliga, de conformidad con reiterada jurisprudencia, a que ese régimen presente las garantías necesarias para evitar cualquier riesgo de que dicho régimen se utilice como sistema de control político del contenido de las resoluciones judiciales. A este respecto, el establecimiento de normas que definan, en particular, tanto los comportamientos constitutivos de infracciones disciplinarias como las sanciones concretamente aplicables, que prevean la intervención de un órgano independiente con arreglo a un procedimiento que garantice plenamente los derechos consagrados en los arts. 47 y 48 de la Carta, especialmente el derecho de defensa, y que consagren la posibilidad de impugnar judicialmente las decisiones de los órganos disciplinarios, da lugar a un conjunto de garantías esenciales para preservar la independencia del Poder Judicial.

Pues bien, según el Tribunal de Justicia, Polonia, en primer lugar, no ha garantizado la independencia y la imparcialidad de la Sala Disciplinaria y, de este modo, ha menoscabado la independencia de los jueces al no garantizarles 
que los procedimientos disciplinarios incoados contra ellos sean controlados por un órgano que presente tales garantías. Conforme al principio de separación de poderes, debe garantizarse la independencia de los tribunales frente a los poderes legislativo y ejecutivo. Pues bien, en virtud de la reforma legislativa de 2017, el proceso de nombramiento de los jueces del Tribunal Supremo y, en particular, el de los miembros de la Sala Disciplinaria del Tribunal Supremo está esencialmente determinado por el CNPJ —órgano este que ha sido remodelado considerablemente por los Poderes Ejecutivo y Legislativo polacos-. El Tribunal de Justicia señala asimismo que se dispone que la Sala Disciplinaria ha de estar integrada exclusivamente por nuevos jueces seleccionados por el CNPJ que no formaran ya parte del Tribunal Supremo y que disfrutarán, en particular, de una retribución muy alta y de un grado de autonomía organizativa, funcional y financiera particularmente elevado en comparación con las condiciones existentes en las demás salas del Tribunal Supremo. El conjunto de estos elementos puede generar dudas legítimas, en el ánimo de los justiciables, en cuanto a la impermeabilidad de tal órgano disciplinario con respecto a influencias directas o indirectas de los poderes legislativo y ejecutivo polacos y a su neutralidad ante los intereses en litigio.

En segundo lugar, el Tribunal de Justicia indica que Polonia ha permitido que el contenido de las resoluciones judiciales pueda calificarse de infracción disciplinaria en lo que respecta a los jueces de los tribunales ordinarios. El Tribunal de Justicia reconoce que la salvaguardia de esta independencia no puede conllevar, en particular, que se excluya totalmente que un juez pueda incurrir en responsabilidad disciplinaria, en determinados supuestos excepcionalísimos, por resoluciones judiciales que haya dictado. En efecto, tal exigencia de independencia evidentemente no tiene por objeto amparar eventuales conductas graves y totalmente inexcusables de los jueces, que consistan, por ejemplo, en incumplir deliberadamente y con mala fe, o por negligencias particularmente graves y groseras, las normas del Derecho nacional y de la Unión por cuyo respeto deben velar, o en actuar con arbitrariedad o incurriendo en denegación de justicia, cuando, como depositarios de la función jurisdiccional, deben resolver los litigios que les plantean los justiciables. En cambio, resulta esencial, con el fin de proteger dicha independencia y evitar de este modo que el régimen disciplinario pueda ser desviado de sus finalidades legítimas y utilizarse con fines de control político de las resoluciones judiciales o de presión sobre los jueces, que el hecho de que una resolución judicial contenga un posible error en la interpretación y la aplicación de las normas del derecho nacional o del de la Unión, o en la apreciación de los hechos y la valoración de las pruebas, no pueda, por sí solo, dar lugar a que se genere la responsabilidad disciplinaria del juez en cuestión. Por consiguiente, es importante que la responsabilidad disciplinaria de un juez por una resolución judicial 
esté limitada a supuestos excepcionalísimos y se delimite, a este respecto, por criterios objetivos y verificables, relativos a los imperativos basados en la buena administración de justicia, así como por garantías destinadas a evitar cualquier riesgo de presiones externas sobre el contenido de las resoluciones judiciales y que permitan excluir de este modo toda duda legítima, en el ánimo de los justiciables, en lo que respecta a la impermeabilidad de los jueces de que se trate y a su neutralidad ante los intereses en litigio.

En tercer lugar, por un lado, Polonia tampoco ha garantizado que los asuntos disciplinarios seguidos contra los jueces de los tribunales ordinarios se examinen en un plazo razonable, menoscabando así una vez más su independencia. En efecto, según el nuevo régimen disciplinario, un juez que haya sido objeto de un procedimiento disciplinario concluido mediante resolución judicial firme puede volver a ser objeto de tales procedimientos en el mismo asunto, de modo que dicho juez queda permanentemente sujeto a la potencial amenaza de tales procedimientos. Por otro lado, las nuevas normas procesales aplicables en materia de procedimientos disciplinarios contra los jueces pueden restringir el derecho de defensa de los jueces inculpados. En efecto, con arreglo a este nuevo régimen, los actos relacionados con la designación de la representación letrada de un juez y con la asunción por aquella de la defensa de este no paralizan el procedimiento, además de que el procedimiento puede desarrollarse pese a la ausencia justificada del juez o de su letrado. Asimismo, singularmente cuando se incardinan, como en el caso de autos, en el contexto de un régimen disciplinario que presenta las deficiencias señaladas, las nuevas normas procesales pueden tender a incrementar el riesgo de utilización del régimen disciplinario como sistema de control político del contenido de las resoluciones judiciales.

En cuarto lugar, el Tribunal de Justicia declara que, al atribuir al presidente de la Sala Disciplinaria la facultad discrecional para designar al tribunal disciplinario competente en primera instancia en los procedimientos disciplinarios seguidos contra los jueces de los tribunales ordinarios, Polonia no ha garantizado que tales asuntos sean enjuiciados por un tribunal «establecido por la ley», como exige también el art. 19 TUE, apdo. 1, párr. segundo.

En segundo término, el Tribunal de Justicia declara que, al permitir que el derecho de los órganos jurisdiccionales a plantear peticiones de decisión prejudicial al Tribunal de Justicia quede limitado debido a la posibilidad de que se incoe un procedimiento disciplinario, Polonia ha incumplido las obligaciones que le incumben en virtud del art. 267 TFUE, párrs. segundo y tercero. En efecto, no cabe admitir unas disposiciones nacionales de las que resulta que los jueces nacionales pueden exponerse a procedimientos disciplinarios por haber planteado al Tribunal de Justicia una remisión prejudicial, por cuanto socavan el ejercicio efectivo por los jueces nacionales afectados 
de la facultad o de la obligación de consultar al Tribunal de Justicia que se establecen en estos preceptos, así como el sistema de cooperación entre los órganos jurisdiccionales nacionales y el Tribunal de Justicia que de esta forma se consagra en los Tratados con la finalidad de garantizar la unidad en la interpretación y la plena eficacia del derecho de la Unión.

El Tribunal de Justicia se pronuncia sobre una serie de reformas rumanas relativas a la organización judicial y al régimen disciplinario de los magistrados, así como a la responsabilidad patrimonial del Estado y a la responsabilidad personal de los jueces por un error judicial (Sentencia de 18 de mayo de 2021, Asociaţia "Forumul Judecătorilor Din România» $y$ otros, C-83/19, C-127/19, C-195/19, C-291/19, C-355/19 y C-397/19, EU:C:2021:393).

El Tribunal de Justicia recibió seis peticiones de decisión prejudicial formuladas por órganos jurisdiccionales rumanos en el marco de litigios entre personas físicas o jurídicas y autoridades u órganos como la Inspección Judicial rumana, el Consejo Superior de la Magistratura y la Fiscalía del Tribunal Supremo. Los litigios principales se inscribían en el marco de una reforma de envergadura en materia de justicia y de lucha contra la corrupción en Rumanía, reforma que es objeto de seguimiento a escala de la Unión Europea desde 2007 en virtud del mecanismo de cooperación y verificación establecido por la Decisión 2006/928/CE de la Comisión, por la que se establece un mecanismo de cooperación y verificación de los avances logrados por Rumanía para cumplir indicadores concretos en materia de reforma judicial y lucha contra la corrupción («MCV»).

En el contexto de las negociaciones para su adhesión a la Unión, en 2004 Rumanía adoptó tres leyes, denominadas «Leyes sobre la justicia» y relativas al estatuto de los jueces y fiscales, a la organización judicial y al Consejo Superior de la Magistratura, con el fin de mejorar la independencia y la eficacia de la justicia. Estas leyes fueron modificadas entre los años 2017 y 2019 mediante leyes y decretos leyes adoptados sobre la base de la Constitución rumana. Los demandantes en los litigios principales cuestionan la compatibilidad con el derecho de la Unión de algunas de esas modificaciones legislativas. En apoyo de sus demandas se refieren a determinados dictámenes e informes elaborados por la Comisión Europea sobre los avances logrados por Rumanía en el marco del MCV.

En este contexto, los órganos jurisdiccionales remitentes se preguntaban sobre la naturaleza y los efectos jurídicos del MCV, así como sobre el alcance de los informes elaborados por la Comisión en virtud de este último. Según esos órganos jurisdiccionales, el contenido, el carácter y la extensión temporal del citado Mecanismo deben considerarse comprendidos en el ámbito de aplicación Tratado de Adhesión y las exigencias formuladas en dichos informes 
deben ser vinculantes para Rumanía. A este respecto, tales órganos jurisdiccionales mencionan, sin embargo, una jurisprudencia nacional según la cual el derecho de la Unión no prevalece sobre el ordenamiento constitucional rumano y la Decisión 2006/928 no puede constituir una norma de referencia para un control de constitucionalidad, toda vez que fue adoptada antes de la adhesión de Rumanía a la Unión y que la cuestión de si su contenido, su carácter y su extensión temporal están comprendidos en el ámbito de aplicación del Tratado de Adhesión no ha sido objeto de interpretación por el Tribunal de Justicia.

En primer lugar, el Tribunal de Justicia, constituido en Gran Sala, declara que la Decisión 2006/928 y los informes elaborados por la Comisión sobre la base de esta última constituyen actos adoptados por una institución de la Unión, susceptibles de ser interpretados con arreglo al art. 267 TFUE. El Tribunal de Justicia añade que, por lo que respecta a su naturaleza jurídica, a su contenido y a sus efectos en el tiempo, la citada decisión está comprendida en el ámbito de aplicación del Tratado de Adhesión, ya que constituye una medida adoptada sobre la base del Acta de Adhesión que vincula a Rumanía desde la fecha de su adhesión a la Unión.

El Tribunal de Justicia declara que, por lo que respecta a sus efectos jurídicos, la Decisión 2006/928 tiene en todos sus elementos carácter vinculante para Rumanía desde su adhesión a la Unión y obliga a este Estado a alcanzar los indicadores concretos, igualmente vinculantes, que figuran en su anexo. Estos indicadores, definidos como consecuencia de las deficiencias comprobadas por la Comisión antes de la adhesión de Rumanía a la Unión, pretenden, en particular, garantizar que el citado Estado miembro respeta el valor del Estado de Derecho.

En lo que atañe a los efectos jurídicos de los informes elaborados por la Comisión sobre la base de la Decisión 2006/928, el Tribunal de Justicia precisa que tales informes formulan exigencias con respecto a Rumanía y dirigen a dicho Estado miembro «recomendaciones» con vistas a la consecución de los indicadores concretos. Conforme al principio de cooperación leal, Rumanía debe tener en cuenta debidamente esas exigencias y recomendaciones y, en los ámbitos cubiertos por los indicadores concretos, debe abstenerse de adoptar o de mantener medidas que puedan poner en peligro el resultado prescrito por esas mismas exigencias y recomendaciones.

En un segundo momento, tras haber declarado que las normas que regulan la organización de la justicia en Rumanía están comprendidas en el ámbito de aplicación de la Decisión 2006/928, el Tribunal de Justicia recuerda que la propia existencia de un control jurisdiccional efectivo destinado a garantizar el respeto del derecho de la Unión es inherente al valor del Estado de Derecho, protegido por el Tratado de la Unión Europea. Subraya a continuación que 
todo Estado miembro debe garantizar que los tribunales que, como «órganos jurisdiccionales», participan en su sistema de medios de impugnación en los ámbitos cubiertos por el derecho de la Unión cumplen las exigencias de la tutela judicial efectiva. Dado que se aplican a los jueces ordinarios que deben pronunciarse sobre cuestiones vinculadas a la aplicación o a la interpretación del derecho de la Unión, las normativas nacionales controvertidas deben satisfacer tales exigencias. Es primordial a este respecto la preservación de la independencia de los jueces en cuestión, con el fin de protegerlos de injerencias o de presiones externas y de excluir así no solo toda influencia directa, sino también las formas de influencia más indirecta que puedan orientar las decisiones de los jueces de que se trata.

Por último, el Tribunal de Justicia señala, en relación con las normas que rigen el régimen disciplinario de los jueces, que la exigencia de independencia obliga a establecer las garantías necesarias para evitar que este régimen se utilice como un sistema de control político del contenido de las resoluciones judiciales. De ello deduce que una normativa nacional no puede suscitar en los justiciables dudas sobre la utilización de las prerrogativas de un órgano judicial encargado de investigaciones y de acciones disciplinarias contra jueces y fiscales como instrumento de presión sobre la actividad de estos últimos o como instrumento de ese tipo de control.

A la luz de estas consideraciones generales, el Tribunal de Justicia declara que una normativa nacional puede suscitar tales dudas cuando tiene como efecto, incluso provisionalmente, permitir que el Gobierno del Estado miembro en cuestión proceda a nombramientos para los puestos directivos del órgano cuya misión es llevar a cabo las investigaciones disciplinarias y ejercer la acción disciplinaria contra jueces y fiscales, eludiendo el procedimiento ordinario de nombramiento previsto por el Derecho nacional.

En un tercer momento, el Tribunal de Justicia examina la compatibilidad con el derecho de la Unión de una normativa nacional que prevé la creación de una sección especializada del Ministerio Fiscal que dispone de competencia exclusiva para investigar las infracciones cometidas por los jueces y fiscales. El Tribunal de Justicia precisa que, para ser compatible con el derecho de la Unión, esa normativa debe, por una parte, estar justificada por imperativos objetivos y verificables relativos a la buena administración de justicia y, por otra, garantizar que tal sección no puede utilizarse como instrumento de control político de la actividad de dichos jueces y fiscales y que ejerce su competencia respetando las exigencias de la Carta de los Derechos Fundamentales. De no cumplirse tales exigencias la citada normativa podría ser percibida en el sentido de que pretende establecer un instrumento de presión e intimidación con respecto a los jueces, lo que menoscabaría la confianza de los justiciables en la justicia. El Tribunal de Justicia añade que la normativa 
nacional controvertida no puede tener como efecto ignorar las obligaciones específicas que incumben a Rumanía en virtud de la Decisión 2006/928 en materia de lucha contra la corrupción.

Incumbe al juez nacional comprobar que la reforma que ha llevado en Rumanía a la creación de una sección especializada del Ministerio Fiscal encargada de las investigaciones respecto de jueces y fiscales, así como las normas relativas al nombramiento de los fiscales adscritos a esa sección, no pueden convertir a esta última en permeable a las influencias externas. En lo relativo a la Carta, corresponde al juez nacional comprobar que la normativa nacional controvertida no obsta para que se oiga dentro de un plazo razonable la causa de los jueces y fiscales de que se trata.

En un cuarto momento, el Tribunal de Justicia declara que una normativa nacional que regula la responsabilidad patrimonial del Estado y la responsabilidad personal de los jueces por los daños causados por un error judicial solo puede ser compatible con el derecho de la Unión en la medida en que la imputación a un juez, en el marco de una acción de repetición, de la responsabilidad personal por tal error judicial se limite a casos excepcionales y esté circunscrita por criterios objetivos y verificables relativos a imperativos derivados de la buena administración de la justicia y por garantías que eviten todo riesgo de presiones externas en el contenido de las resoluciones judiciales. Son esenciales para ello normas claras y precisas que definan los comportamientos que pueden generar la responsabilidad personal de los jueces, con el fin de garantizar la independencia inherente a su misión y de evitar que por el mero hecho de resolver queden expuestos al riesgo de incurrir en responsabilidad personal. El hecho de que una decisión contenga un error judicial no puede bastar por sí solo para generar la responsabilidad personal del juez de que se trate.

En cuanto al procedimiento para declarar la responsabilidad personal de los jueces, la normativa nacional debe establecer de manera clara y precisa las garantías necesarias para evitar la apariencia de que la investigación destinada a comprobar la existencia de las condiciones y circunstancias que pueden generar dicha responsabilidad o la acción de repetición puedan transformarse en instrumentos de presión sobre la actividad jurisdiccional. Con el fin de evitar que tal procedimiento pueda producir un efecto disuasorio sobre los jueces en el ejercicio de su misión de juzgar con total independencia, las propias autoridades competentes deben ser autoridades que actúen de manera objetiva e imparcial para iniciar y llevar a cabo esa investigación y para ejercitar dicha acción, y tanto los requisitos materiales como la regulación procesal deben ser tales que no puedan suscitar dudas legítimas acerca de la imparcialidad de esas autoridades. Es igualmente necesario el pleno respeto de los derechos consagrados por la Carta, en particular el derecho de defensa del 
juez, y que el órgano competente para pronunciarse sobre la responsabilidad personal del juez sea un órgano jurisdiccional. En particular, la constatación de la existencia de un error judicial no puede tomarse como hecho probado en el ejercicio por parte del Estado de la acción de repetición contra el juez de que se trata, sin que este siquiera haya sido oído en el anterior procedimiento dirigido a que se declare la responsabilidad patrimonial del Estado.

En un quinto momento, el Tribunal de Justicia declara que el principio de primacía del derecho de la Unión se opone a una normativa nacional de rango constitucional que priva a un órgano jurisdiccional de rango inferior del derecho a abstenerse de aplicar, por su propia iniciativa, una disposición nacional comprendida en el ámbito de aplicación de la Decisión 2006/928 y contraria al derecho de la Unión. El Tribunal de Justicia recuerda que, según jurisprudencia consolidada, los efectos que se asocian al principio de primacía del derecho de la Unión vinculan a todos los órganos de un Estado miembro, sin que puedan oponerse a él, en particular, las disposiciones internas relativas al reparto de las competencias judiciales, incluidas las de rango constitucional. Recordando asimismo que los órganos jurisdiccionales nacionales están obligados a dar al derecho interno, en la medida de lo posible, una interpretación conforme con las exigencias del derecho de la Unión, o a abstenerse de aplicar, por su propia iniciativa, cualquier disposición contraria de la legislación nacional que no pueda ser objeto de tal interpretación conforme, el Tribunal de Justicia hace constar que, en caso de infracción comprobada del Tratado UE o de la Decisión 2006/928, el principio de primacía del derecho de la Unión exige que el órgano jurisdiccional remitente se abstenga de aplicar las disposiciones controvertidas, ya sean de origen legislativo o constitucional.

\section{En determinadas condiciones, una autoridad de control nacional puede ejercer su facultad de poner en conocimiento de los órganos jurisdiccio- nales de ese Estado miembro cualquier supuesta infracción del RGPD, aunque no sea la autoridad de control principal en lo referente a ese tratamiento (Sentencia de 15 de junio de 2021, Facebook Ireland y otros, C645/19, EU:C:2021:483).}

En septiembre de 2015, el presidente de la Comisión belga de protección de la vida privada («CPVP») ejercitó ante el Tribunal de Primera Instancia Neerlandófono de Bruselas, una acción de cesación contra Facebook Ireland, Facebook Inc. y Facebook Belgium, que tenía por objeto poner fin a infracciones de la legislación en materia de protección de datos supuestamente cometidas por Facebook. Estas infracciones consistían, en particular, en la recogida y utilización de información sobre los hábitos de navegación de 
los internautas belgas, poseedores o no de una cuenta Facebook, mediante diferentes tecnologías, como cookies, complementos sociales o píxeles.

Dicho órgano jurisdiccional se declaró competente para conocer de esa acción y, en cuanto al fondo, declaró que la red social Facebook no había informado suficientemente a los internautas belgas de la recogida y del uso de dicha información. Además, no se consideró válido el consentimiento dado por los internautas para la recogida y el tratamiento de la información. Facebook Ireland, Facebook Inc. y Facebook Belgium interpusieron recurso de apelación contra esa sentencia ante el Hof van beroep te Brussel (Tribunal de Apelación de Bruselas, Bélgica), que es el órgano jurisdiccional remitente en el presente asunto. Ante este órgano jurisdiccional, la Autoridad de Protección de Datos belga («APD») ha actuado como sucesor legal del presidente de la CPVP.

El órgano jurisdiccional remitente albergaba dudas acerca de los efectos de la aplicación del mecanismo de "ventanilla única» previsto por el Reglamento (UE) 2016/679 del Parlamento Europeo y del Consejo, relativo a la protección de las personas físicas en lo que respecta al tratamiento de datos personales y a la libre circulación de estos datos ( $(\mathrm{RGPD} »)$. A tenor del art. 56, apdo. 1, del RGPD, «sin perjuicio de lo dispuesto en el artículo 55, la autoridad de control del establecimiento principal o del único establecimiento del responsable o del encargado del tratamiento será competente para actuar como autoridad de control principal para el tratamiento transfronterizo realizado por parte de dicho responsable o encargado». Se preguntaba si, con respecto a los hechos posteriores a la entrada en vigor del RGPD, la APD puede ejercitar acciones judiciales contra Facebook Belgium, dado que Facebook Ireland ha sido identificada como la responsable del tratamiento de los datos en cuestión. En efecto, desde esta fecha y, en particular, en aplicación del principio de "ventanilla única» establecido por el RGPD, el comisario irlandés de protección de datos es el único competente para ejercitar una acción de cesación, bajo el control de los órganos jurisdiccionales irlandeses.

En primer lugar, el Tribunal de Justicia precisa las condiciones en las que una autoridad nacional de control, que no tiene la condición de autoridad principal con respecto a un tratamiento transfronterizo, debe ejercer su facultad de poner en conocimiento de los órganos jurisdiccionales de un Estado miembro cualquier supuesta infracción del RGPD y, si procede, iniciar o ejercitar acciones judiciales para garantizar la aplicación de este reglamento. Así, por una parte, el RGPD debe conferir a dicha autoridad de control una competencia para adoptar una decisión en la que se declare que dicho tratamiento incumple las normas que contiene ese reglamento y, por otra parte, esa facultad debe ejercerse respetando los procedimientos de cooperación y de 
coherencia establecidos por dicho reglamento (establecidos en los arts. 56 y 60 del RGPD).

En efecto, en el caso de los tratamientos transfronterizos, el RGPD establece el mecanismo de «ventanilla única», basado en un reparto de competencias entre una "autoridad de control principal» y las demás autoridades de control interesadas. Este mecanismo exige una cooperación estrecha, leal y efectiva entre estas autoridades, para garantizar una protección coherente y homogénea de las normas relativas a la protección de datos personales y preservar así su efecto útil. El RGPD establece a este respecto la competencia de principio de la autoridad de control principal para adoptar una decisión en la que se declare que un tratamiento transfronterizo incumple las normas establecidas en dicho Reglamento (art. 60, apdo. 7, del RGPD), mientras que la competencia de las demás autoridades nacionales de control para adoptar tal decisión, incluso con carácter provisional, constituye la excepción. El art. 56, apdo. 2, y el art. 66 del RGPD establecen las excepciones al principio de la competencia decisoria de la autoridad de control principal

No obstante, en el ejercicio de sus competencias, la autoridad de control principal no puede prescindir de un diálogo indispensable y de una cooperación leal y efectiva con las demás autoridades de control interesadas. Por ello, en el marco de esta cooperación, la autoridad de control principal no puede pasar por alto los criterios de las demás autoridades de control interesadas, y toda objeción pertinente y motivada formulada por una de estas últimas autoridades tiene por efecto bloquear, al menos temporalmente, la adopción del proyecto de decisión de la autoridad de control principal.

El Tribunal de Justicia precisa, además, que el hecho de que una autoridad de control de un Estado miembro que no sea la autoridad de control principal con respecto a un tratamiento de datos transfronterizo solo pueda ejercer la facultad de poner en conocimiento de los órganos jurisdicciones de ese Estado miembro cualquier supuesta infracción del RGPD y de iniciar o ejercitar acciones judiciales respetando las reglas de reparto de la competencias decisorias entre la autoridad de control principal y las demás autoridades de control (establecidas en los arts. 55 y 56, en combinación con el art. 60 del RGPD) es conforme con los arts. 7, 8 y 47 de la Carta de los Derechos Fundamentales de la Unión Europea, que garantizan al interesado, respectivamente, el derecho a la protección de datos de carácter personal y el derecho a la tutela judicial efectiva.

En segundo lugar, el Tribunal de Justicia declara que, en caso de tratamiento de datos transfronterizo, el ejercicio de la facultad de una autoridad de control de un Estado miembro, distinta de la autoridad de control principal, de iniciar o ejercitar acciones judiciales (en virtud del art. 58, apdo. 5, del RGPD) no exige que el responsable o encargado del tratamiento transfronterizo de 
datos personales contra el que se ejercite dicha acción disponga de un establecimiento principal u otro establecimiento en el territorio de dicho Estado miembro. Sin embargo, el ejercicio de esta facultad debe estar comprendida en el ámbito de aplicación territorial del RGPD, lo que supone que el responsable o el encargado del tratamiento transfronterizo disponga de un establecimiento en el territorio de la Unión.

En tercer lugar, el Tribunal de Justicia declara que, en caso de tratamiento de datos transfronterizo, la facultad de una autoridad de control de un Estado miembro, distinta de la autoridad de control principal, de poner en conocimiento de los órganos jurisdiccionales de este Estado cualquier supuesta infracción de dicho reglamento $y$, si procede, iniciar o ejercitar acciones judiciales puede ejercerse tanto con respecto al establecimiento principal del responsable del tratamiento que se encuentra en el Estado miembro de dicha autoridad como con respecto a otro establecimiento de ese responsable, siempre que la acción judicial tenga por objeto un tratamiento de datos efectuado en el contexto de las actividades de ese establecimiento y que dicha autoridad tenga competencia para ejercer esa facultad.

Sin embargo, el Tribunal de Justicia precisa que el ejercicio de esta facultad supone que el RGPD sea aplicable. En el presente asunto, dado que las actividades del establecimiento del grupo Facebook situado en Bélgica están indisociablemente vinculadas al tratamiento de los datos personales de que se trata en el litigio principal, de los que Facebook Ireland es el responsable en lo que se refiere al territorio de la Unión, este tratamiento se realiza «en el contexto de las actividades de un establecimiento del responsable» y, por tanto, está efectivamente comprendido en el ámbito de aplicación del RGPD.

En cuarto lugar, el Tribunal de Justicia declara que, cuando una autoridad de control de un Estado miembro que no es la «autoridad de control principal» ejercitó, antes de la fecha de entrada en vigor del RGPD, una acción judicial cuyo objeto era un tratamiento transfronterizo de datos personales, dicha acción puede mantenerse, desde el punto de vista del derecho de la Unión, sobre la base de las disposiciones de la Directiva 95/46/CE del Parlamento Europeo y del Consejo, relativa a la protección de las personas físicas en lo que respecta al tratamiento de datos personales y a la libre circulación de estos datos, que sigue siendo aplicable en lo que se refiere a las infracciones de las normas que establece, cometidas hasta la fecha en la que dicha directiva fue derogada. Además, dicha acción puede ser ejercitada por esa autoridad por infracciones cometidas después de la fecha de entrada en vigor del RGPD, siempre que sea en una de las situaciones en las que, excepcionalmente, dicho reglamento confiere a esa misma autoridad competencia para adoptar una decisión por la que se declare que el tratamiento de datos de que se trata no 
cumple las disposiciones de dicho reglamento y siempre que se respeten los procedimientos de cooperación que este último establece.

El derecho de la Unión sobre protección de datos se opone a la normativa letona que obliga a la autoridad de seguridad vial a hacer accesibles al público los datos relativos a puntos impuestos a conductores por infracciones de tráfico, pues no se ha demostrado la necesidad de este régimen para garantizar el objetivo perseguido, a saber, la mejora de la seguridad vial [Sentencia de 22 de junio de 2021, Latvijas Republikas Saeima (Puntos de penalización), C-439/19, EU:C:2021:504].

A B, persona física, se le impusieron puntos por una o varias infracciones de tráfico. Estos puntos fueron inscritos en el registro nacional de vehículos y conductores. En virtud de la normativa letona sobre circulación vial, la información relativa a los puntos impuestos a conductores inscritos en dicho registro es accesible al público y es comunicada a cualquier persona que lo solicite, sin que se tenga que justificar un interés específico en obtener dicha información, incluidos operadores económicos a efectos de reutilización. Al albergar dudas sobre la legalidad de esta normativa, B interpuso un recurso de inconstitucionalidad ante el Tribunal Constitucional de Letonia, para que este órgano jurisdiccional examinara la conformidad de dicha normativa con el derecho al respeto de la vida privada. El Tribunal Constitucional consideró, en el marco de su apreciación de dicho derecho constitucional, que debía tener en cuenta el Reglamento (UE) 2016/679 del Parlamento Europeo y del Consejo, relativo a la protección de las personas físicas en lo que respecta al tratamiento de datos personales y a la libre circulación de estos datos («RGPD»).

En primer lugar, el Tribunal de Justicia considera que el tratamiento de datos personales relativos a los puntos constituye un «tratamiento de datos personales relativos a condenas e infracciones penales» (art. 10 del RGPD), para el que el RGPD prevé una mayor protección debido al carácter especialmente sensible de los datos en cuestión. En este contexto, observa, con carácter preliminar, que la información relativa a los puntos es datos personales y que su comunicación por parte de la CSDD a terceros constituye un tratamiento comprendido en el ámbito de aplicación material del RGPD. En efecto, dicho ámbito de aplicación es muy amplio y ese trato no está comprendido en las excepciones a la aplicabilidad del reglamento.

Así pues, por una parte, dicho tratamiento no está cubierto por la excepción relativa a la no aplicación del RGPD a un tratamiento efectuado en el marco de una actividad no comprendida en el ámbito de aplicación del derecho de la Unión [art. 2, apdo. 2, letra a), del RGPD]. Debe conside- 
rarse que la citada excepción tiene como único objeto excluir del ámbito de aplicación del RGPD el tratamiento de datos personales efectuado por autoridades estatales en el marco de una actividad dirigida a preservar la seguridad nacional o de una actividad que pueda incluirse en la misma categoría. Estas actividades comprenden, en particular, las que tienen por objeto proteger las funciones esenciales del Estado y los intereses fundamentales de la sociedad. Ahora bien, las actividades relativas a la seguridad vial no persiguen este objetivo y, por lo tanto, no pueden incluirse en la categoría de las actividades que tienen por objeto la preservación de la seguridad nacional.

Por otra parte, la comunicación de datos personales relativos a los puntos tampoco es un tratamiento comprendido por la excepción que prevé que no se aplique el RGPD al tratamiento de datos personales efectuado por las autoridades competentes en materia penal [art. 2, apdo. 2, letra d), del RGPD]. El Tribunal de Justicia observa, en efecto, que no puede considerarse que, en el ejercicio de dicha comunicación, la CSDD sea una de esas «autoridades competentes», en el sentido del art. 3, apdo. 7, de la Directiva (UE) 2016/680 del Parlamento Europeo y del Consejo, relativa a la protección de las personas físicas en lo que respecta al tratamiento de datos personales por parte de las autoridades competentes para fines de prevención, investigación, detección o enjuiciamiento de infracciones penales o de ejecución de sanciones penales, y a la libre circulación de dichos datos.

Para determinar si el acceso a los datos personales relativos a infracciones de tráfico, como los puntos, constituye un tratamiento de datos personales relativos a «infracciones» (art. 10 de RGPD), los cuales gozan de una mayor protección, el Tribunal de Justicia constata, basándose en particular en la génesis del RGPD, que este concepto se refiere exclusivamente a las infracciones penales. No obstante, el hecho de que, en el sistema jurídico letón, las infracciones de tráfico estén tipificadas como infracciones administrativas no es determinante para apreciar si tales infracciones están comprendidas en el concepto de «infracción penal», en la medida en que se trata de un concepto autónomo del derecho de la Unión que exige, en toda la Unión, una interpretación autónoma y uniforme. Así pues, tras recordar los tres criterios pertinentes para apreciar el carácter penal de una infracción, a saber, la calificación jurídica de la infracción en derecho interno, la naturaleza de la infracción y el grado de severidad de la sanción impuesta, el Tribunal de Justicia declara que las infracciones de tráfico en cuestión están comprendidas en el concepto de «infracción» en el sentido del RGPD. Por lo que respecta a los dos primeros criterios, el Tribunal de Justicia constata que, aunque las infracciones no se califiquen de "penales» en derecho nacional, tal carácter puede derivarse de la naturaleza de la infracción y, especialmente, de la finalidad represiva que persiga la sanción que la propia infracción puede 
implicar. Pues bien, en el caso de autos, la atribución de puntos por infracciones de tráfico, al igual que las demás sanciones que la comisión de aquellas puede implicar, persiguen, entre otras cosas, tal finalidad represiva. En cuanto al tercer criterio, el Tribunal de Justicia observa que solo las infracciones de tráfico de cierta gravedad implican la imposición de puntos y que, por lo tanto, pueden dar lugar a sanciones de cierta severidad. Además, la imposición de tales puntos se suma generalmente a la sanción impuesta, y la acumulación de estos puntos conlleva consecuencias jurídicas que pueden incluso llegar a la prohibición de conducir.

En segundo lugar, el Tribunal de Justicia considera que el RGPD se opone a la normativa letona que obliga a la CSDD a poner a disposición del público los datos relativos a puntos impuestos a conductores por infracciones de tráfico sin que la persona que solicita el acceso tenga que justificar un interés específico en obtenerlos.

En este contexto, el Tribunal de Justicia subraya que la mejora de la seguridad vial que persigue la normativa letona es un objetivo de interés general reconocido por la Unión y que, por tanto, los Estados miembros pueden calificar la seguridad vial de "misión realizada en interés público», en el sentido del art. 6, apdo. 1, letra e), del RGPD. Sin embargo, no se ha demostrado la necesidad del régimen letón de comunicación de datos personales relativos a los puntos para lograr el objetivo perseguido. En efecto, por una parte, el legislador letón dispone de numerosas vías de acción que le habrían permitido alcanzar este objetivo por otros medios menos atentatorios contra los derechos fundamentales de las personas afectadas. Por otra parte, deben tenerse en cuenta el carácter sensible de los datos relativos a los puntos y el hecho de que su comunicación al público puede constituir una injerencia grave en los derechos al respeto de la vida privada y a la protección de los datos personales, ya que puede provocar la desaprobación de la sociedad y conllevar la estigmatización de la persona afectada.

Además, el Tribunal de Justicia considera que, habida cuenta del carácter sensible de estos datos y de la gravedad de la injerencia en esos dos derechos fundamentales, dichos derechos prevalecen tanto sobre el interés del público en tener acceso a documentos oficiales, por ejemplo, el registro nacional de vehículos y conductores, como sobre el derecho a la libertad de información.

En tercer lugar, por idénticas razones, el Tribunal de Justicia declara que el RGPD se opone también a la normativa letona en la medida en que autoriza a la CSDD a comunicar los datos relativos a los puntos impuestos a conductores por infracciones de tráfico a operadores económicos para que estos puedan reutilizarlos y comunicarlos al público.

En cuarto y último lugar, el Tribunal de Justicia precisa que el principio de primacía del derecho de la Unión se opone a que el órgano jurisdiccional 
remitente, que es el que conoce del recurso interpuesto contra la normativa letona calificada por el Tribunal de Justicia de incompatible con el derecho de la Unión, decida mantener los efectos jurídicos de dicha normativa hasta la fecha en que dicho órgano jurisdiccional remitente dicte sentencia firme.

El Tribunal de Justicia desestima el recurso de Hungría contra la Resolución del Parlamento por la que se da inicio al procedimiento de constatación de la existencia de un riesgo claro de violación grave, por parte de este Estado miembro, de los valores en los que se fundamenta la Unión, pues al calcular los votos emitidos con ocasión de la aprobación de dicha Resolución, el Parlamento excluyó válidamente las abstenciones (Sentencia de 3 de junio de 2021, Hungría/Parlamento, C-650/18, EU:C:2021:426).

El 12 de septiembre de 2018, el Parlamento Europeo adoptó una resolución sobre una propuesta en la que solicitaba al Consejo de la Unión Europea que, de conformidad con el art. 7 TUE, apdo. 1, constatara la existencia de un riesgo claro de violación grave por parte de Hungría de los valores comunes en los que se fundamenta la Unión. Esta constatación dio inicio al procedimiento del art. 7 TUE, que puede conducir a la suspensión de determinados derechos derivados de la pertenencia del Estado miembro de que se trata a la Unión.

En virtud del art. 354 TFUE, párr. cuarto, que establece el régimen de votación a efectos de la aplicación del art. 7 TUE, la aprobación por el Parlamento de la resolución controvertida requería recabar una mayoría de dos tercios de los votos emitidos que representara la mayoría de los miembros que lo componen. En aplicación del art. 178, apdo. 3, del Reglamento interior del Parlamento, que dispone que, al calcular si se ha aprobado o rechazado un texto, solo se computarán los votos «a favor» $\mathrm{y}$ "en contra», excepto cuando en los Tratados se establezca una determinada mayoría, el Parlamento solamente tuvo en cuenta, al calcular los votos en relación con la resolución controvertida, los votos favorables y desfavorables de sus miembros y excluyó las abstenciones. Al considerar que, a efectos del cómputo de los votos emitidos, el Parlamento debería haber computado las abstenciones, Hungría interpuso, con arreglo al art. 263 TFUE, un recurso por el que solicitó la anulación de dicha Resolución.

En primer término, el Tribunal de Justicia se pronuncia sobre su competencia para resolver el recurso y seguidamente sobre su admisibilidad. Señala, para empezar, que el art. 269 TFUE, que contempla una posibilidad limitada de interponer recurso de anulación contra los actos adoptados por el Consejo Europeo o por el Consejo en el marco del procedimiento del art. 7 TUE, no 
excluye la competencia del Tribunal de Justicia para conocer del recurso. En efecto, al someter ese derecho de recurso a requisitos más estrictos que los impuestos por el art. 263 TFUE, el art. 26 TFUE entraña una limitación a la competencia general del Tribunal de Justicia para controlar la legalidad de los actos de las instituciones de la Unión y, por tanto, debe interpretarse restrictivamente. Además, las resoluciones del Parlamento adoptadas con arreglo al art. 7 TUE, apdo. 1, no se mencionan en el art. 269 TFUE. Así pues, los autores de los Tratados no pretendieron excluir un acto como la resolución impugnada de la competencia general que el art. 263 TFUE reconoce al Tribunal de Justicia.

A continuación, el Tribunal de Justicia declara que la resolución impugnada es un acto recurrible. En efecto, produce efectos jurídicos obligatorios desde su adopción, ya que, mientras el Consejo no se haya pronunciado sobre el curso que debe dársele, tiene como efecto inmediato que se levante la prohibición a la que están sometidos los Estados miembros de tomar en consideración o declarar admisibles para su examen las solicitudes de asilo presentadas por nacionales húngaros, en virtud del art. único, letra b), del Protocolo (n. ${ }^{\circ}$ 24) sobre asilo a nacionales de los Estados miembros de la Unión Europea.

Además, la resolución impugnada no constituye un acto de trámite cuya legalidad solo pueda impugnarse con ocasión de un litigio relativo al acto definitivo del que constituya una fase de elaboración. En efecto, por una parte, al adoptar dicha resolución, el Parlamento no expresó una postura provisional, aun cuando la constatación ulterior por el Consejo de la existencia de un riesgo claro de violación grave por parte de un Estado miembro de los valores de la Unión esté supeditada a la previa aprobación del Parlamento. Por otra parte, la resolución impugnada produce efectos jurídicos autónomos puesto que, aun cuando el Estado miembro de que se trata pudiera invocar la ilegalidad de esta resolución en apoyo del recurso de anulación que interpusiera contra la constatación del Consejo, la eventual estimación de tal recurso no permitiría, en cualquier caso, suprimir todos los efectos obligatorios desplegados por dicha resolución.

El Tribunal de Justicia subraya, no obstante, que determinados requisitos específicos que se establecen en el art. 269 TFUE, a los que se sujeta la interposición de un recurso de anulación dirigido contra la constatación del Consejo que puede adoptarse a raíz de una propuesta motivada del Parlamento como la resolución impugnada, deben aplicarse también al recurso de anulación dirigido, en virtud del art. 263 TFUE, contra tal propuesta motivada, a fin de que el art. 269 TFUE no quede privado de su efecto útil. Así pues, tal recurso de anulación solo puede ser interpuesto por el Estado miembro al que dicha propuesta motivada se refiera y los motivos de anulación esgrimidos en apoyo 
de tal recurso únicamente pueden fundarse en la infracción de las reglas de procedimiento contempladas en el art. 7 TUE.

En segundo lugar, en relación con el fondo del asunto, el Tribunal de Justicia observa que el concepto de "votos emitidos» que figura en el art. 354 TFUE, párr. cuarto, no se define en los Tratados y que este concepto autónomo del derecho de la Unión debe interpretarse conforme a su sentido habitual en el lenguaje corriente. Pues bien, este concepto, en su sentido habitual, solo engloba la manifestación de un voto positivo o negativo sobre una determinada propuesta, mientas que la abstención, que se entiende como la negativa a posicionarse, no puede ser asimilada a un «voto emitido». Por lo tanto, debe interpretarse que la norma establecida en el art. 354 TFUE, párr. cuarto, que impone una mayoría de los votos emitidos, excluye que se tengan en cuenta las abstenciones.

Dicho esto, tras haber recordado que el art. 354 TFUE, párr. cuarto, implica una doble mayoría, a saber, que los actos adoptados por el Parlamento en virtud del art. 7 TUE, apdo. 1, deben recabar, por una parte, dos tercios de los votos emitidos y, por otra, la mayoría de los miembros del Parlamento, el Tribunal de Justicia indica que, en cualquier caso, las abstenciones se toman en consideración para comprobar que los votos favorables representen la mayoría de los miembros del Parlamento.

\section{CONTENCIOSO}

Se anula por insuficiencia de motivación la Decisión de la Junta Única de Resolución sobre el cálculo de las aportaciones ex ante al Fondo Único de Resolución para 2017 en lo que respecta a Landesbank Baden-Württemberg, si bien el Tribunal de Justicia anula la sentencia de ese Tribunal General por haber violado el principio de contradicción y no haber apreciado correctamente el alcance de la obligación de motivación (Sentencia de 15 de julio de 2021, Comisión/Landesbank Baden-Württemberg y Junta Única de Resolución, C-584/20 P y C-621/20 P, EU:C:2021:601).

En abril de 2017, la Junta Única de Resolución (JUR) adoptó, en el marco de la financiación del Fondo Único de Resolución (FUR), una decisión por la que se fijaba el importe de las aportaciones ex ante adeudadas al FUR por cada entidad de crédito correspondientes al año 2017. Entre esas entidades figuraba Landesbank Baden-Württemberg, una entidad de crédito alemana. A raíz de un recurso de anulación interpuesto por Landesbank Baden-Württemberg, el Tribunal General anuló la decisión controvertida en la medida 
en que afectaba a dicha entidad (T-411/17, EU:T:2020:435). Entendió que esta decisión no satisfacía el requisito de autenticación y, en aras de una buena administración de justicia, declaró además que la referida Decisión había sido adoptada por la JUR incumpliendo la obligación de motivación. A este respecto, concluyó en particular que la decisión controvertida no contenía casi ningún dato útil para el cálculo de la contribución ex ante al FUR y que su anexo no contenía información suficiente para verificar la exactitud de esa contribución.

En primer lugar, el Tribunal de Justicia señala que el Tribunal General violó el principio de contradicción por cuanto no ofreció a la JUR la posibilidad de pronunciarse eficazmente sobre el motivo, planteado de oficio por el Tribunal General, referido a la falta de prueba suficiente de la autenticación del anexo de la decisión controvertida.

A este respecto, el Tribunal de Justicia recuerda que, con el fin de garantizar el respeto efectivo del principio de contradicción, debe instarse a las partes a que, con carácter previo, presenten sus observaciones sobre el motivo que el órgano jurisdiccional de la Unión tiene intención de examinar de oficio, en unas condiciones que les permitan pronunciarse de manera útil y efectiva sobre ese motivo, aportando también, en su caso, las pruebas necesarias para que el referido órgano jurisdiccional pueda resolver sobre dicho motivo plenamente informado. Por lo tanto, incumbía al Tribunal General informar a las partes de su intención de fundar su decisión en el motivo basado en la falta de autenticación de la decisión controvertida e instarlas consecuentemente a que presentaran las alegaciones que consideraran convenientes para que pudiera resolver sobre el expresado motivo. Pues bien, en este caso, el Tribunal General no ofreció efectivamente a la JUR, ni en la vista ni antes de este acto, la posibilidad de pronunciarse eficazmente sobre ese motivo, en particular presentando pruebas relacionadas con la autenticación de la decisión controvertida.

Tras hacer constar, pues, que el Tribunal General había violado el principio de contradicción, el Tribunal de Justicia declara que la JUR garantizó suficientemente, en conjunto, la autenticación de la decisión controvertida, tanto por lo que se refiere a su texto principal como a su anexo, en particular mediante la utilización del sistema informático «ARES».

En segundo lugar, el Tribunal de Justicia se pronuncia sobre la obligación de motivación que pesa sobre la JUR para la adopción de una decisión como la decisión controvertida. En primer término, señala que el Tribunal General no apreció correctamente el alcance de esa obligación, en la medida en que consideró que la JUR estaba obligada a exponer en la motivación de la decisión controvertida los datos que permitieran a Landesbank BadenWürttemberg comprobar que el cálculo de su contribución ex ante al FUR 
para 2017 era exacto, sin que el carácter confidencial de algunos de esos datos afectara de alguna forma a dicha obligación.

Por un lado, la motivación de cualquier decisión de una institución, de un órgano o de un organismo de la Unión que imponga a un operador privado el pago de una cantidad de dinero no debe necesariamente incluir todos los datos que permitan a su destinatario comprobar la exactitud del cálculo del importe reclamado. Por otro lado, las instituciones, órganos y organismos de la Unión están obligados en principio, con arreglo al imperativo de la protección del secreto comercial, como principio general del derecho de la Unión, a no revelar a los competidores de un operador privado la información confidencial que este les haya facilitado.

Teniendo en cuenta el funcionamiento del sistema de financiación del FUR y el método de cálculo de las aportaciones ex ante al FUR, que se basa en particular en la utilización de datos confidenciales relativos a la situación financiera de las entidades a las que concierne ese cálculo, la obligación de motivación de la decisión controvertida debe ponderarse con la obligación de la JUR de respetar el secreto comercial de dichas entidades. No obstante, esta última obligación no debe interpretarse en un sentido tan amplio que vacíe la obligación de motivación de su contenido esencial. En este sentido, motivar una decisión por la que se impone a un operador privado el pago de una suma de dinero sin proporcionarle todos los datos que permitan comprobar con exactitud el cálculo del importe reclamado no menoscaba necesariamente, en todos los casos, el contenido esencial de la obligación de motivación.

De esta manera, el Tribunal de Justicia concluye que, en este caso, la obligación de motivación se ha respetado si los destinatarios de una decisión por la que se fijan aportaciones ex ante al FUR pueden acceder, sin que se les transmitan datos protegidos por el secreto comercial, al método de cálculo utilizado por la JUR y disponen de información suficiente para comprender, en esencia, de qué manera se tuvo en cuenta su situación individual, a efectos del cálculo de su contribución ex ante al FUR, en relación con la situación del resto de las entidades afectadas.

A continuación, el Tribunal de Justicia no comparte el parecer del Tribunal General según el cual la violación de la obligación de motivación de la JUR tenía su causa, por la parte del cálculo de las aportaciones ex ante al FUR relativa al ajuste en función del perfil de riesgo de las entidades afectadas, en la ilegalidad de determinadas disposiciones del Reglamento Delegado (UE) 2015/63 de la Comisión, por el que se completa la Directiva 2014/59/UE del Parlamento Europeo y del Consejo, en lo que respecta a las contribuciones ex ante a los mecanismos de financiación de la resolución. En la sentencia recurrida, el Tribunal General declaró ilegales los arts. 4 a 7 y 9 y el anexo I 
de este reglamento, que tratan del método de cálculo de las contribuciones ex ante al FUR.

Tras detallar el mecanismo de ajuste de las aportaciones ex ante al FUR al perfil de riesgo, que se basa esencialmente en la asignación de las entidades afectadas a «intervalos» en función de determinados valores, lo que permite, a la postre, determinar el multiplicador de ajuste al riesgo, el Tribunal de Justicia indica que la JUR puede divulgar, sin incumplir su obligación de respetar el secreto comercial, los valores límite de los «intervalos» y los indicadores correspondientes. Esa divulgación tiene por objeto permitir a la entidad de que se trate cerciorarse, en particular, de que la clasificación que se le ha atribuido en la operación de discretización de los indicadores corresponde efectivamente a su situación económica, que tal discretización se ha realizado de conformidad con el método definido por el Reglamento Delegado 2015/63 sobre la base de datos verosímiles y que se han tenido en cuenta todos los factores de riesgo.

Por añadidura, las otras etapas del método de cálculo de las aportaciones ex ante al FUR se basan en datos globales de las entidades afectadas, que pueden divulgarse en forma colectiva sin quebrantar la obligación de la JUR de respetar el secreto comercial.

Por lo tanto, el Tribunal de Justicia concluye que el Reglamento Delegado 2015/63 no impide a la JUR divulgar, en forma colectiva y anonimizada, información suficiente que permita a una entidad comprender de qué manera se ha tenido en cuenta su situación individual a la hora de calcular su contribución ex ante al FUR en relación con la situación del resto de las entidades afectadas. Es cierto que una motivación basada en información pertinente divulgada en forma colectiva y anonimizada no permite a cada entidad detectar sistemáticamente un eventual error cometido por la JUR en la recopilación y la agregación de los datos pertinentes. En cambio, tal motivación es suficiente para permitir a esa entidad asegurarse de que la información que facilitó a las autoridades competentes se ha integrado efectivamente en el cálculo de su contribución ex ante al FUR, de conformidad con las normas del derecho de la Unión pertinentes, e identificar, basándose en sus conocimientos generales del sector financiero, una eventual utilización de información carente de verosimilitud o manifiestamente incorrecta, así como determinar si procede interponer un recurso de anulación contra una decisión de la JUR por la que se fije su contribución ex ante al FUR. El Tribunal de Justicia precisa, no obstante, que tales consideraciones sobre la motivación de una decisión como la decisión controvertida deben entenderse sin perjuicio de la posibilidad de que los órganos jurisdiccionales de la Unión, con el fin de ejercer una tutela judicial efectiva conforme a las exigencias del art. 47 de la Carta de los Derechos Fundamentales de la Unión Europea, soliciten a la JUR que presente datos que justifiquen los cálculos cuya exactitud se ha impugnado en 
el correspondiente procedimiento judicial, garantizando si fuera necesario la confidencialidad de esos datos.

El Tribunal de Justicia declara, por último, que la decisión controvertida no está suficientemente motivada porque los datos que figuran en ella, así como los accesibles en el sitio de Internet de la JUR en la fecha de la referida decisión, no comprenden más que una parte de la información pertinente que la JUR hubiera podido comunicar sin vulnerar el secreto comercial. En particular, ni el anexo de esa decisión ni el sitio de Internet de la JUR aportaban datos relativos a los valores límite de cada «intervalo» y a los valores de los indicadores correspondientes. Por consiguiente, se anula la decisión controvertida en lo que respecta a Landesbank Baden-Württemberg.

El Tribunal de Justicia desestima los recursos de casación que tenían por objeto la anulación de los actos del BCE que concluyeron que unos bancos estaban en graves dificultades o probablemente iban a estarlo, pues el Tribunal General declaró correctamente que los recursos eran inadmisibles, al considerar que los actos recurridos constituían actos preparatorios en el procedimiento que debía permitir a la Junta Única de Resolución adoptar una resolución (Sentencia de 6 de mayo de 2021, ABLV Bank/BCE, C-551/19 P y C-552/19 P, EU:C:2021:369).

Los recurrentes son ABLV Bank AS, que es una entidad de crédito establecida en Letonia y la sociedad matriz del grupo ABLV (C-551/19 P), y una serie de accionistas de ABLV Bank AS (C-552/19 P). ABLV Bank Luxembourg SA es una entidad de crédito establecida en Luxemburgo, que constituye una de las filiales del grupo ABLV y ABLV Bank es su accionista único. Esas dos entidades de crédito estaban consideradas entidades significativas y estaban, por ello, sujetas a la supervisión del Banco Central Europeo (BCE) en el marco del Mecanismo Único de Supervisión instaurado por el Reglamento (UE) n. ${ }^{\circ}$ 1024/2013 («Reglamento MUS»).

El 13 de febrero de 2018, el United States Department of the Treasury (Departamento del Tesoro de los Estados Unidos de América) expresó su intención de adoptar medidas especiales para impedir al grupo ABLV tener acceso al sistema financiero en dólares estadounidenses (USD). A raíz de ese anuncio, el grupo se encontró en dificultades, lo que provocó el inicio del examen de la adopción de una resolución prevista por el Reglamento (UE) n. ${ }^{\circ}$ 806/2014 del Parlamento Europeo y del Consejo, por el que se establecen normas uniformes y un procedimiento uniforme para la resolución de entidades de crédito y de determinadas empresas de servicios de inversión en el marco de un Mecanismo Único de Resolución y un Fondo Único de Resolución («Reglamento MUR»). El procedimiento de resolución es un 
procedimiento complejo que, según los casos, requiere la intervención de distintas autoridades europeas, como el BCE, la Junta Única de Resolución ("Junta»), la Comisión Europea y el Consejo de la Unión Europea, así como las autoridades nacionales de resolución afectadas.

En caso de autos, el 18 de febrero de 2018, el BCE instó a la Comisión de Mercados Financieros y de Capitales («CMFC»), autoridad nacional de resolución de Letonia, a imponer una moratoria para permitir que ABLV Bank pudiera estabilizar su situación. Instó también a la Comisión de Supervisión del Sector Financiero, autoridad nacional de resolución de Luxemburgo, a adoptar medidas similares frente a ABLV Bank Luxembourg.

Conforme al Reglamento MUR, el 22 de febrero de 2018, el BCE comunicó a la Junta su proyecto de evaluación relativa a la situación de graves dificultades en que ABLV Bank y ABLV Bank Luxembourg estaban o probablemente iban a estar. El 23 de febrero de 2018, el BCE consideró que ABLV Bank y ABLV Bank Luxembourg estaban en graves dificultades o probablemente iban a estarlo, de conformidad con el art. 18, apdo. 1, párr. primero, letra a), del Reglamento MUR. Ese mismo día, no obstante, la Junta consideró que no era necesario adoptar frente a dichas entidades una medida de resolución en aras del interés público.

Los recurrentes solicitaron la anulación de los actos del BCE que concluyeron que los referidos bancos estaban en graves dificultades o probablemente iban a estarlo. Mediante autos de 6 de mayo de 2019, el Tribunal General declaró los recursos inadmisibles, al considerar que los actos recurridos constituían actos preparatorios en el procedimiento que debía permitir a la Junta adoptar una resolución. El Tribunal de Justicia desestima los recursos de casación de los recurrentes. En su sentencia, lleva a cabo una distinción entre las funciones de la Junta y del BCE.

Mediante su primer motivo de casación, los recurrentes alegaban que, para apreciar la admisibilidad de los recursos, el Tribunal General debería haber tomado en consideración la evaluación de la inviabilidad de los bancos llevada a cabo por el BCE. El Tribunal de Justicia considera que el Tribunal General no infringió la jurisprudencia con arreglo a la cual, para apreciar la admisibilidad de un recurso, es preciso atenerse al contenido esencial del acto recurrido, gracia a los criterios objetivos que son su contenido, el contexto en el que se adoptó y las facultades de la institución que fue su autora. Por otra parte, el Tribunal General no cometió un error al tener en cuenta también la intención del $\mathrm{BCE}$, otorgando no obstante a ese criterio subjetivo un papel complementario.

Según el Tribunal de Justicia, es erróneo presumir que todos los actos de las instituciones tienen carácter decisorio, a menos que se haya indicado expresamente que no sucede así. Aplicar tal presunción sería contrario a 
la jurisprudencia que el Tribunal de Justicia recuerda en esta sentencia. Para responder a las alegaciones de los recurrentes, el Tribunal de Justicia señala que la apreciación, por parte del BCE, de la proporcionalidad de la medida en cuestión no es un elemento suficiente que acredite el carácter vinculante de ese acto de apreciación. En efecto, toda medida debe respetar los principios generales del derecho de la Unión, en particular el principio de proporcionalidad, de tal modo que la proporcionalidad de una medida puede analizarse en un acto intermedio durante un procedimiento administrativo que incluya varias fases. Respecto al hecho de que el BCE lleva a cabo la comunicación y publicación de los actos controvertidos, ello no implica que haya querido conferir a dichos actos un carácter vinculante o que tengan de por sí ese carácter. En lo que se refiere a la afirmación, por parte del $\mathrm{BCE}$, de la inevitable liquidación de las entidades de crédito, el Tribunal de Justicia señala que esa liquidación no se derivó de los actos del BCE, sino de una decisión adoptada por los accionistas a raíz de la decisión de la Junta en virtud de la cual no era necesario en aras del interés público aplicar dispositivos de resolución.

Antes de responder al segundo motivo de casación, el Tribunal de Justicia subraya las características del Reglamento MUR. Uno de los objetivos de ese reglamento es la adopción de decisiones rápidas, con el fin de que no se ponga en peligro la estabilidad financiera. Pues bien, el reconocimiento del carácter decisorio de la evaluación por parte del BCE acerca de si una entidad está en graves dificultades o probablemente vaya a estarlo podría afectar sensiblemente a la celeridad del procedimiento. Por otra parte, el Tribunal de Justicia señala que el hecho de prever un recurso jurisdiccional únicamente frente a las decisiones de la Junta (art. 86, apdo. 2, del Reglamento MUR) parece confirmar que el legislador de la Unión no pretendió conferir una competencia decisoria al BCE en la materia.

El Tribunal de Justicia recuerda que la Junta solo puede adoptar un dispositivo de resolución cuando se cumplen tres condiciones, previstas en el art. 18, apdo. 1, párr. primero, letras a) a c), del Reglamento MUR: que la entidad esté en graves dificultades o probablemente vaya a estarlo, que no existan perspectivas razonables de que otras medidas puedan impedir su inviabilidad en un plazo de tiempo razonable y que la medida de resolución sea necesaria para el interés público.

El Tribunal de Justicia señala que la evaluación por parte del BCE acerca de si una entidad está en graves dificultades o probablemente vaya a estarlo solo se refiere a una de esas condiciones. El Tribunal de Justicia señala por otra parte que la evaluación es un papel prioritario del BCE debido a sus conocimientos especializados y a su acceso a la información prudencial. No obstante, la Junta puede llevar a cabo dicha evaluación por sí misma, por ejemplo, cuando el BCE considere que la entidad no está en graves dificultades 
o probablemente vaya a estarlo, y dispone de una competencia exclusiva para determinar si se cumplen las tres condiciones. No queda vinculada por la evaluación del BCE y puede no estar de acuerdo con dicha evaluación. Al contrario, es a la Junta a quien corresponde corregir una irregularidad dado que los recursos judiciales se han previsto contra sus resoluciones.

Según el Tribunal de Justicia, el BCE tiene conocimientos especializados como organismo supervisor. No obstante, la distinción entre la supervisión y la resolución de las entidades de crédito no incide en la naturaleza de acto preparatorio de la evaluación: un acto de retirada de una autorización de una entidad no es por tanto equivalente a una evaluación acerca de si una entidad está en graves dificultades o probablemente vaya a estarlo.

El procedimiento de remisión prejudicial puede utilizarse para controlar la validez de las Directrices sobre procedimientos de gobernanza y vigilancia de productos de banca minorista de la Autoridad Bancaria Europea, que el Tribunal de Justicia considera válidas (Sentencia de 15 de julio de 2021, FBF/ACPR, C-911/19, EU:C:2021:599).

En 2016, la Autoridad Bancaria Europea (ABE) emitió unas Directrices sobre procedimientos de gobernanza y vigilancia de productos de banca minorista. Mediante un dictamen publicado en su sitio de Internet la Autorité de contrôle prudentiel et de résolution (Autoridad de Control Prudencial y de Resolución) (ACPR) (France) anunció que cumplía dichas directrices, haciéndolas así aplicables a todas las entidades financieras bajo su ámbito de control. La Fédération bancaire française (FBF) interpuso ante el Conseil d'État (Consejo de Estado, actuando como Tribunal Supremo de lo Contencioso-Administrativo, Francia) un recurso con objeto de obtener la anulación del dictamen de la ACPR. La FBF alegaba que las directrices de la $\mathrm{ABE}$, que dicho dictamen hacía aplicables, no eran válidas porque dicha autoridad carecía de competencia para emitir tales directrices.

$\mathrm{Al}$ albergar dudas, por una parte, en cuanto a las vías de recurso disponibles para garantizar el control de la legalidad de las directrices controvertidas por el juez de la Unión y, por otra parte, en cuanto a la validez de estas directrices a la luz del marco del mandato conferido a la $\mathrm{ABE}$ por el derecho derivado, el Conseil d'État planteó una cuestión prejudicial al Tribunal de Justicia, solicitándole que se pronunciara sobre estos aspectos.

En su sentencia, dictada en Gran Sala, el Tribunal de Justicia, tras constatar, para empezar, que las directrices de la $\mathrm{ABE}$ no podían ser objeto de recurso de anulación con arreglo al art. 263 TFUE, se declaró a continuación competente para apreciar la validez de estas directrices con carácter prejudicial, en virtud del art. 267 TFUE, y confirmó, por último, su validez. 
Por lo que se refiere al control jurisdiccional de las directrices controvertidas por el juez de la Unión, el Tribunal de Justicia señaló que estos actos no pueden ser objeto de un recurso de anulación con arreglo al art. 263 TFUE, ya que no pretenden producir efectos jurídicos obligatorios. A este respecto, subrayó que del art. 16, apdo. 3, del Reglamento (UE) n. ${ }^{\circ}$ 1093/2010 del Parlamento Europeo y del Consejo, por el que se crea una Autoridad Europea de Supervisión (Autoridad Bancaria Europea), se desprende que las autoridades competentes destinatarias de las directrices controvertidas no están obligadas a atenerse a ellas y disponen de la facultad de apartarse de las mismas, en cuyo caso deben motivar su postura. Así pues, no puede considerarse que estas directrices produzcan efectos jurídicos obligatorios con respecto a dichas autoridades competentes o a las entidades financieras. Por consiguiente, según el Tribunal de Justicia, al autorizar a la ABE a emitir directrices y recomendaciones, el legislador de la Unión pretendió conferirle una facultad de incentivación y de persuasión, distinta de la facultad de adoptar actos dotados de fuerza vinculante.

No obstante, el hecho de que las directrices controvertidas carezcan de efectos jurídicos obligatorios no excluye la competencia del Tribunal de Justicia para pronunciarse, con carácter prejudicial, sobre su validez. A este respecto, el Tribunal de Justicia se declaró competente, en virtud del art. 267 TFUE, para apreciar la validez de las directrices controvertidas.

Por consiguiente, apreció esa validez a la luz de las disposiciones del Reglamento n. ${ }^{\circ}$ 1093/2010, con el fin de comprobar si tales directrices forman parte de las competencias de la ABE. Para empezar, subrayó que, dado que del Reglamento n. ${ }^{\circ}$ 1093/2010 se desprende que el legislador de la Unión ha delimitado con precisión la facultad de la $\mathrm{ABE}$ de emitir directrices, sobre la base de criterios objetivos, el ejercicio de dicha facultad debe poder ser objeto de un control judicial riguroso a la luz de esos criterios. El hecho de que las directrices controvertidas no produzcan efectos jurídicos obligatorios no puede afectar al alcance del referido control.

A continuación, el Tribunal de Justicia precisó que la capacidad de acción de la $A B E$ es limitada, en el sentido de que dicha autoridad solo es competente para emitir directrices en la medida expresamente prevista por el legislador de la Unión. Tras recordar el contenido de las disposiciones del Reglamento n. ${ }^{\circ}$ 1093/2010 relativas al alcance de las competencias conferidas a la $\mathrm{ABE}$, el Tribunal de Justicia declaró, por una parte, que la validez de directrices emitidas por dicha autoridad está supeditada al cumplimiento de las disposiciones de dicho reglamento que regulan específicamente la facultad de la ABE para emitirlas, pero también a la inclusión de dichas directrices en el ámbito de actuación de la $\mathrm{ABE}$, que ese mismo reglamento define por referencia a la aplicación de determinados actos de la Unión a los que este 
se refiere. Por otra parte, la $\mathrm{ABE}$ puede, para garantizar una aplicación común, uniforme y coherente del derecho de la Unión, emitir directrices relativas a las obligaciones de supervisión prudencial que recaen sobre las entidades de que se trata, en particular, con el fin de proteger los intereses de los depositantes y de los inversores mediante una regulación adecuada de la asunción de riesgos financieros. En efecto, nada hay en el Reglamento n. ${ }^{\circ}$ 1093/2010 que permita considerar que queden excluidas de esa facultad las medidas relativas al diseño y a la comercialización de los productos, en la medida en que tales medidas se inscriban en el ámbito de actuación de la ABE.

A la luz de estas consideraciones, el Tribunal de Justicia examinó si las directrices controvertidas están comprendidas, por una parte, en el ámbito de actuación de la $\mathrm{ABE}$ y, por otra parte, en el marco específico establecido por el legislador de la Unión para el ejercicio de la facultad de la ABE de emitir directrices. El Tribunal de Justicia concluye que las directrices controvertidas forman efectivamente parte del marco específico adoptado por el legislador de la Unión para el ejercicio de la facultad de la $\mathrm{ABE}$ de emitir directrices $y$, por consiguiente, de las competencias de la $\mathrm{ABE}$, y consideró, por tanto, que el examen de validez solicitado por el órgano jurisdiccional remitente no puso de manifiesto la existencia de ningún elemento que pudiera cuestionar la validez de dichas directrices.

El Tribunal de Justicia considera que goza de una competencia exclusiva, con exclusión de la de los órganos jurisdiccionales nacionales, para conocer de una acción de responsabilidad extracontractual ejercitada por un antiguo agente temporal de la Comisión debido a un comportamiento culposo que imputa al miembro de dicha institución del que él era colaborador y que llevó a esta institución a poner fín a la relación laboral con dicho agente, y que tal acción no debe dirigirse contra el miembro de la Comisión de que se trata, sino contra la Unión, representada por la Comisión (Sentencia de 15 de julio de 2021, OH, C-758/19, EU:C:2021:603).

La petición de decisión prejudicial había planteada por el Polymeles Protodikeio Athinon (Tribunal de Primera Instancia de Atenas, Grecia), y tenía por objeto la interpretación del art. 343 TFUE y de los arts. 11, 17 y 19 del Protocolo n. ${ }^{\circ} 7$ sobre los privilegios y las inmunidades de la Unión Europea. Esta petición se había presentado en el contexto de un litigio entre $\mathrm{OH}$, antiguo agente temporal de la Comisión Europea, e ID, un antiguo comisario europeo de nacionalidad griega, en relación con un comportamiento culposo que $\mathrm{OH}$ imputa a ID y que supuestamente llevó a la Comisión a poner fin al contrato de trabajo de $\mathrm{OH}$. 
El Tribunal de Justicia considera que goza de una competencia exclusiva, con exclusión de la de los órganos jurisdiccionales nacionales, para conocer de una acción de responsabilidad extracontractual ejercitada por un antiguo agente temporal de la Comisión debido a un comportamiento culposo que imputa al miembro de dicha institución del que él era colaborador y que llevó a esta institución a poner fin a la relación laboral con dicho agente. Tal acción no debe dirigirse contra el miembro de la Comisión de que se trata, sino contra la Unión, representada por la Comisión.

En primer lugar, señala que, con arreglo al art. 268 TFUE, en relación con el art. 340 TFUE, párrs. segundo y tercero, el Tribunal de Justicia es competente para conocer de los litigios relativos a la indemnización de los daños causados por las instituciones de la Unión o por sus agentes en el ejercicio de sus funciones. Además, el Tribunal de Justicia es el único competente para pronunciarse sobre los litigios en los que se reclama la responsabilidad extracontractual de la Unión, con exclusión de los órganos jurisdiccionales nacionales. Así sucede, en particular, con una demanda de indemnización por el perjuicio causado por agentes de la Unión como consecuencia de actos que, en virtud de una relación interna y directa, constituyen la prolongación necesaria de las misiones confiadas a las instituciones.

En segundo lugar, como ha precisado el Tribunal de Justicia en numerosas ocasiones, todo litigio entre un funcionario o un agente de la Unión y la institución de la que depende entra dentro del ámbito de aplicación del art. 270 TFUE y del art. 91, apdo. 1, del estatuto, cuando ese litigio tenga su origen en la relación laboral que vincula al interesado con dicha institución, aun cuando se trate de un recurso de indemnización. En el caso de autos, de la petición de decisión prejudicial se desprende que la acción de responsabilidad extracontractual fue ejercitada ante el órgano jurisdiccional remitente por $\mathrm{OH}$, en su condición de antiguo agente temporal de la Comisión, contra un antiguo comisario europeo.

A este respecto, en el litigio principal, el perjuicio alegado deriva de la ruptura de la relación laboral en sí, puesto que el miembro de la Comisión declaró que ya no confiaba en $\mathrm{OH}$. Pues bien, dicha declaración se inscribe necesariamente en el marco del ejercicio de las funciones que tiene encomendadas el miembro de la Comisión. En efecto, esta declaración se formuló en apoyo de la decisión de este según la cual ya no deseaba recurrir a los servicios de $\mathrm{OH}$, decisión que puede tomar en virtud de la facultad que le compete de organizar su gabinete acudiendo a personas con las que mantiene una relación de confianza, para poder realizar lo mejor posible las tareas que se le han encomendado en su condición de comisario europeo. De ello resulta que un comportamiento como el que $\mathrm{OH}$ reprocha al miembro de la Comisión forma parte en realidad de la gestión, por parte de este, del personal de su gabinete. 
Por lo tanto, debe considerarse que tal comportamiento está comprendido indisociablemente en el ejercicio de las funciones de ese miembro, como prolongación necesaria de la misión que se le ha confiado como tal, en el sentido de la jurisprudencia del Tribunal de Justicia.

\section{CIUDADANÍA, LIBRE CIRCULACIÓN Y MERCADO INTERIOR}

Aunque no llega a ser una violación del derecho a la no discriminación por nacionalidad, las autoridades nacionales deben comprobar si la negativa a determinadas prestaciones de asistencia social expone al ciudadano de la Unión y a sus hijos al riesgo de que se vulneren sus derechos consagrados por la Carta de los Derechos Fundamentales y, en particular, el respeto de la dignidad humana (Sentencia de 15 de julio de 2021, C-709/20, CG, EU:C:2021:602).

CG, titular de la doble nacionalidad croata y neerlandesa, vive en el Reino Unido desde el año 2018 sin ejercer actividad económica alguna. En junio de 2020, el Home Office (Ministerio del Interior, Reino Unido) le concedió un derecho de residencia temporal en el Reino Unido, sobre la base de un nuevo régimen británico aplicable a los ciudadanos de la Unión residentes en dicho país, establecido en el contexto de la retirada del Reino Unido de la Unión. La concesión de ese derecho de residencia no está sujeta a un requisito relativo a la suficiencia de recursos. Unos días más tarde, CG presentó una solicitud de prestación de asistencia social, denominada crédito universal (Universal Credit), ante las autoridades competentes. Esta solicitud fue denegada, porque las autoridades consideraron que la ley nacional sobre el crédito universal excluye a los ciudadanos de la Unión que disponen de un derecho de residencia concedido sobre la base del nuevo régimen.

CG impugnó esta denegación ante el tribunal nacional competente invocando, en particular, una diferencia de trato entre los ciudadanos de la Unión que residen legalmente en el Reino Unido y los nacionales británicos. Este tribunal nacional decidió interrogar al Tribunal de Justicia sobre la posible incompatibilidad de la ley británica sobre el crédito universal con la prohibición de discriminación por razón de la nacionalidad, prevista en el art. 18 TFUE, párr. primero. La petición de decisión prejudicial se hizo antes del final del período transitorio, a saber, antes del 31 de diciembre de 2020, por lo que el Tribunal de Justicia es competente para dictar sentencia.

Así, el Tribunal de Justicia, en formación de Gran Sala, examinó la compatibilidad de la ley nacional con el principio de igualdad. En primer lugar, precisó que la cuestión de si CG es víctima de discriminación por razón 
de la nacionalidad debe apreciarse a la luz del art. 24 de la Directiva 2004/38, relativa al derecho de los ciudadanos de la Unión y de los miembros de sus familias a circular y residir libremente en el territorio de los Estados miembros, y no del art. 18 TFUE, puesto que el primero de estos artículos materializa el principio de no discriminación por razón de la nacionalidad consagrado por el segundo.

Tras constatar que el crédito universal en cuestión debe calificarse de prestación de asistencia social, en el sentido de la citada directiva, el Tribunal de Justicia señaló que el acceso a dichas prestaciones está reservado a los ciudadanos de la Unión que cumplen los requisitos enunciados en la misma. A este respecto, el Tribunal de Justicia recordó que, en virtud del art. 7 de dicha directiva, la obligación que incumbe a un ciudadano de la Unión económicamente inactivo de disponer de recursos suficientes constituye un requisito para que este pueda beneficiarse de un derecho de residencia por un período superior a tres meses pero inferior a cinco años.

A continuación, el Tribunal de Justicia confirmó su jurisprudencia según la cual un Estado miembro dispone de la facultad, con arreglo a dicho artículo, de denegar la concesión de prestaciones de asistencia social a ciudadanos de la Unión económicamente inactivos que, al igual que CG, ejercen su libertad de circulación y no disponen de recursos suficientes para optar al derecho de residencia en virtud de dicha directiva. El Tribunal de Justicia precisó que, en el marco del examen concreto de la situación económica de cada interesado, las prestaciones solicitadas no se toman en consideración para determinar la posesión de recursos suficientes.

El Tribunal de Justicia subrayó, por lo demás, que la Directiva 2004/38 no impide a los Estados miembros establecer un régimen más favorable que el previsto por dicha directiva. No obstante, el Tribunal de Justicia matizó esta conclusión al declarar que, de conformidad con el art. 51, apdo. 1, de la Carta de los Derechos Fundamentales, las autoridades nacionales están obligadas, al examinar una solicitud de prestaciones de asistencia social como la presentada por CG, a dar cumplimiento a las disposiciones de dicha Carta y, en particular, a sus arts 1 (dignidad humana), 7 (respeto de la vida privada y familiar) y 24 (derechos del niño). En el marco de este examen, dichas autoridades pueden tener en cuenta el conjunto de los mecanismos de apoyo establecidos por el derecho nacional de que pueden beneficiarse efectivamente el ciudadano afectado y sus hijos.

Un ciudadano de la Unión que haya sido objeto de una decisión de expulsión solo podrá disfrutar de un nuevo derecho de residencia en el territorio del Estado miembro de acogida una vez que haya puesto fin 


\section{a su estancia en dicho territorio de manera real y efectiva (Sentencia de 22 de junio de 2021, FS, C-719/19, EU:C:2021:506).}

En este asunto el Tribunal de Justicia examinó los requisitos y los efectos de una decisión de expulsión de un ciudadano de la Unión. Los hechos relevantes se remontan a 2018 cuando las autoridades neerlandesas consideraron que FS, de nacionalidad polaca, se encontraba en situación de residencia irregular en el territorio de los Países Bajos, puesto que ya no cumplía los requisitos relativos al derecho de residencia por más de tres meses, y dictó una orden para que abandonara el territorio neerlandés.

FS había abandonado los Países Bajos, dado que la policía alemana lo detuvo en esa fecha por un robo en una tienda. FS declaró que residía en Alemania, cerca de la frontera neerlandesa. Indicó asimismo que, debido a su dependencia de la marihuana, acudía diariamente a los Países Bajos para comprar esta sustancia. En efecto, unos meses más tarde, fue detenido en un supermercado situado en los Países Bajos por un robo. A raíz de su detención y de su internamiento policial, el secretario de Estado neerlandés decretó el internamiento administrativo de FS con el fin de expulsarlo a su país de origen. Esta última decisión se basó en el riesgo de que FS se sustrajera a la vigilancia de extranjería y evitara u obstaculizara los preparativos de su salida o del procedimiento de expulsión.

El Tribunal de Primera Instancia de La Haya declaró infundado el recurso interpuesto por FS contra la decisión de internamiento administrativo. FS recurrió esta última resolución ante el Consejo de Estado de los Países Bajos, el órgano jurisdiccional remitente. Según el juez nacional, la legalidad del internamiento de FS a su regreso da los Países Bajos depende de la cuestión de si disfrutaba de un nuevo derecho de residencia en la fecha de ese internamiento.

El Tribunal de Justicia, en formación de Gran Sala, declaró que una decisión de expulsión de un ciudadano de la Unión del territorio del Estado miembro de acogida no se ha ejecutado plenamente por el mero hecho de que dicho ciudadano de la Unión haya abandonado físicamente ese territorio dentro del plazo que dicha decisión establece para su salida voluntaria. Para disfrutar de un nuevo derecho de residencia en el mismo territorio, el ciudadano de la Unión contra el que se haya dictado tal decisión de expulsión no solo debe haber abandonado físicamente el territorio del Estado miembro de acogida, sino también haber puesto fin a su residencia en ese territorio de manera real y efectiva, de modo que, con ocasión de su regreso a dicho territorio, no pueda considerarse que su estancia se inscribe, en realidad, en la continuidad de su residencia anterior en ese mismo territorio. 
Para llegar a esta conclusión, en primer lugar, el Tribunal de Justicia señaló que una interpretación en el sentido de que la mera salida física del ciudadano de la Unión es suficiente a efectos de la ejecución de una decisión de expulsión conduciría a permitirle invocar múltiples estancias temporales sucesivas en un Estado miembro con el fin de residir en él, en realidad, de forma permanente, cuando lo cierto es que dicho ciudadano no cumpliría los requisitos del derecho de residencia permanente previstos por la Directiva sobre el derecho de residencia.

En segundo lugar, el Tribunal de Justicia proporcionó indicaciones útiles al órgano jurisdiccional remitente para que este pueda determinar, sobre la base de una apreciación global de todas las circunstancias del litigio del que conoce, si el ciudadano de la Unión de que se trata ha puesto fin a su residencia en el territorio del Estado miembro de acogida de manera real y efectiva, de modo que la decisión de expulsión de la que ha sido objeto ha sido plenamente ejecutada. A este respecto, en primer lugar, imponer a ese ciudadano, en todos los casos, que se ausente del Estado miembro de acogida durante un período mínimo, por ejemplo, de tres meses, para poder invocar un nuevo derecho de residencia en ese Estado miembro, equivaldría a supeditar el ejercicio de ese derecho fundamental a una limitación no prevista en el derecho de la Unión. Sin embargo, la duración del período pasado por esa persona fuera del territorio del Estado miembro de acogida tras la adopción de la decisión de expulsión puede revestir cierta importancia, en la medida en que, cuanto más prolongada sea la ausencia del interesado del territorio del Estado miembro de acogida, con mayor consistencia queda acreditado el carácter real y efectivo de la finalización de su residencia. Por otra parte, el Tribunal de Justicia subrayó la importancia de todos los elementos que acreditan la ruptura de los vínculos que unen al ciudadano de la Unión de que se trate con el Estado miembro de acogida, como la rescisión de un contrato de alquiler o una mudanza. El Tribunal de Justicia precisó que la pertinencia de tales elementos debe ser apreciada por la autoridad nacional competente a la luz del conjunto de circunstancias concretas que caracterizan la situación específica del ciudadano de la Unión de que se trate.

Por último, el Tribunal de Justicia precisó las consecuencias de la no ejecución de una decisión de expulsión. En efecto, si se comprueba que el ciudadano de la Unión no ha puesto fin a su residencia temporal en el territorio del Estado miembro de acogida de manera real y efectiva, ese Estado miembro no está obligado a adoptar una nueva decisión de expulsión sobre la base de los mismos hechos que dieron lugar a la decisión de expulsión ya adoptada contra ese ciudadano, sino que puede basarse en esta última decisión para obligar a este a abandonar su territorio. No obstante, una decisión de expulsión adoptada contra un ciudadano de la Unión no se le puede oponer 
cuando ese ciudadano se desplace puntualmente a dicho territorio con fines distintos de los de residir en él.

Las medidas de ejecución de una decisión de expulsión de un ciudadano de la Unión y de los miembros de su familia por razones de orden o de seguridad públicos constituyen restricciones del derecho de circulación y de residencia que pueden estar justificadas cuando se basan exclusivamente en la conducta personal del interesado y se ajustan al principio de proporcionalidad, pero la duración máxima de internamiento de ocho meses prevista por el Derecho belga va más allá de lo necesario para garantizar una política eficaz de expulsión (Sentencia de 22 de junio de 2021, Ordre des barreaux francophones et germanophone y otros, C-718/19, EU:C:2021:505).

En otro asunto sobre los efectos de una decisión de expulsión, dictada el mismo día que la sentencia anterior, el Tribunal de Justicia, a raíz de una petición de decisión prejudicial formulada por el Tribunal Constitucional belga, examinó la conformidad con el derecho de la Unión de una normativa nacional que prevé, por una parte, la posibilidad de imponer a los ciudadanos de la Unión medidas preventivas para evitar cualquier riesgo de fuga, tales como un arresto domiciliario. Por otra parte, permite internar durante un período máximo de ocho meses a los ciudadanos de la Unión y a los miembros de sus familias que no hayan dado cumplimiento a tal decisión de expulsión, con el fin de garantizar su ejecución. Estas disposiciones son similares o idénticas a las aplicables a los nacionales de terceros países en situación irregular.

El Tribunal de Justicia, constituido en Gran Sala, constató, con carácter preliminar, que, a falta de normativa del derecho de la Unión sobre la ejecución de una decisión de expulsión de los ciudadanos de la Unión y de los miembros de sus familias, el mero hecho de que el Estado miembro de acogida establezca normas en el marco de esta ejecución inspirándose en las aplicables al retorno de los nacionales de terceros países no es, en sí mismo, contrario al derecho de la Unión. No obstante, tales normas deben ser conformes con el derecho de la Unión, en particular, en materia de libertad de circulación y de residencia de los ciudadanos de la Unión y de los miembros de sus familias. Las disposiciones nacionales de que se trata, en tanto limitan los movimientos del interesado, constituyen restricciones a la libertad de circulación y de residencia.

En segundo lugar, en lo que concierne a la existencia de justificaciones para tales restricciones, el Tribunal de Justicia recordó de entrada que las medidas en cuestión pretenden garantizar la ejecución de decisiones de expulsión adoptadas por razones de orden público o de seguridad pública. Las 
medidas preventivas para evitar el riesgo de fuga contribuyen necesariamente a la protección del orden público, en tanto su objetivo es garantizar que una persona que represente una amenaza para el orden público del Estado miembro de acogida sea expulsada de su territorio, y pueden estar justificadas. No obstante, estas medidas q no pueden ser menos favorables que las medidas previstas en el derecho nacional para evitar el riesgo de fuga, durante el plazo de salida voluntaria, de los nacionales de terceros países que son objeto de un procedimiento de retorno por razones de orden público.

Por añadidura, el Tribunal de Justicia consideró que el derecho de la Unión (arts. 20 TFUE y 21 TFUE y la Directiva 2004/38) se opone, va más allá de lo necesario para alcanzar el objetivo perseguido, a una normativa nacional que aplica a los ciudadanos de la Unión y a los miembros de sus familias, que, tras la expiración del plazo establecido o de la prórroga de dicho plazo, no han dado cumplimiento a una decisión de expulsión adoptada en su contra por razones de orden público o seguridad pública, una medida de internamiento por un período máximo de ocho meses, siendo este período idéntico al aplicable, en el derecho nacional, a los nacionales de terceros países que no hayan dado cumplimiento a una decisión de retorno. A este respecto, el Tribunal de Justicia indicó que la duración del internamiento, que es idéntica a la aplicable al internamiento de los nacionales de terceros países, debe ser proporcionada al objetivo perseguido, consistente en garantizar una política eficaz de expulsión de los ciudadanos de la Unión y de los miembros de sus familias. Ahora bien, por lo que respecta específicamente a la duración del procedimiento de expulsión, los ciudadanos de la Unión y los miembros de sus familias no se encuentran en una situación comparable a la de los nacionales de terceros países, de modo que no está justificado conceder un trato idéntico a todas esas personas en lo que atañe a la duración máxima del internamiento. En particular, los Estados miembros disponen de mecanismos de cooperación y de facilidades en el contexto de la expulsión de los ciudadanos de la Unión o de los miembros de sus familias a otro Estado miembro de los que no disponen necesariamente en el marco de la expulsión de un nacional de un tercer país a un tercer país.

Para que pueda considerarse que una empresa de trabajo temporal «ejerce normalmente sus actividades» en un Estado miembro, debe realizar una parte sustancial de su actividad de cesión de trabajadores en favor de empresas usuarias que estén establecidas y ejerzan sus actividades en el territorio de dicho Estado miembro (Sentencia de 3 de junio de 2021, C-784/19, Team Power Europe, EU:C:2021:427). 
En este asunto, el Tribunal de Justicia, en formación de Gran Sala, delimitó, por lo que respecta a las empresas de trabajo temporal y el alcance del concepto de empresario que ejerce normalmente sus actividades en un Estado miembro, previsto en dicha disposición y que precisa el art. 14, apdo. 2, del Reglamento n. ${ }^{0} 987 / 2009$, por el que se adoptan las normas de aplicación del Reglamento (CE) n. ${ }^{\circ} 883 / 2004$, sobre la coordinación de los sistemas de seguridad social.

Durante el año 2018, un nacional búlgaro celebró un contrato de trabajo con Team Power Europe, sociedad búlgara cuyo objeto social es el desarrollo de actividades de trabajo temporal y de intermediación en la búsqueda de empleo en Bulgaria y en otros países. En virtud de dicho contrato, el nacional búlgaro fue cedido a una empresa usuaria establecida en Alemania. Entre el 15 de octubre y el 21 de diciembre de 2018, el interesado debía desempeñar su trabajo bajo la dirección y la supervisión de la empresa alemana.

Al considerar, por una parte, que no se había mantenido la relación directa entre Team Power Europe y el trabajador en cuestión y, por otra parte, que dicha empresa no llevaba a cabo una actividad sustancial en territorio búlgaro, la autoridad competente búlgara desestimó la solicitud de Team Power Europe por la que esta sociedad pedía la expedición de un certificado A1 que acreditara que la legislación búlgara de seguridad social era aplicable al trabajador en cuestión durante el período de su cesión. Consideró que la situación del trabajador no estaba comprendida en el ámbito de aplicación del art. 12, apdo. 1, del Reglamento n. ${ }^{\circ} 883 / 2004$, sobre la coordinación de los sistemas de seguridad social, en virtud del cual la legislación búlgara habría sido aplicable. Team Power Europe impugnó esta resolución administrativa ante los tribunales nacionales.

En este contexto, el tribunal nacional que resolvía del caso en apelación, decidió preguntar al Tribunal de Justicia acerca de los criterios pertinentes que deben tenerse en cuenta para apreciar si una empresa de trabajo temporal ejerce normalmente actividades sustanciales distintas de la mera gestión interna en el territorio del Estado miembro en el que está establecida, en el sentido del art. 14, apdo. 2, del Reglamento n. ${ }^{0}$ 987/2009.

El Tribunal de Justicia procedió, en primer lugar, a una interpretación literal del citado art. 14, apdo. 2 del Reglamento n. ${ }^{\circ}$ 987/2009, y señaló que una empresa de trabajo temporal se caracteriza por el hecho de ejercer un conjunto de actividades consistentes en seleccionar, contratar y suministrar trabajadores a empresas usuarias. A este respecto, el Tribunal de Justicia indicó que, aunque las actividades de selección y de contratación de trabajadores para su cesión no pueden considerarse "actividades de mera gestión interna" en el sentido de dicha disposición, el desempeño de las referidas actividades en el Estado miembro en el que está establecida una empresa de ese tipo no 
basta para considerar que ejerce «actividades sustanciales» en él. En efecto, el único propósito de las actividades de selección y contratación de trabajadores por empresas de trabajo temporal estriba en que las referidas empresas cedan posteriormente esos trabajadores a las empresas usuarias.

A continuación, el Tribunal de Justicia subrayó que, por más que la selección y la contratación de trabajadores contribuyan ciertamente a generar el volumen de negocios de una empresa de trabajo temporal, puesto que esas actividades constituyen un requisito previo indispensable para la ulterior cesión de tales trabajadores, solo la cesión de esos trabajadores a empresas usuarias en cumplimiento de los contratos celebrados a tal fin con dichas empresas genera de modo efectivo a ese volumen de negocios. En efecto, los ingresos de una empresa de este tipo dependen del importe de la retribución abonada a los trabajadores que se ponen a disposición de las empresas usuarias.

Seguidamente, por lo que respecta al contexto en el que se inscribe la disposición analizada, el Tribunal de Justicia recordó que el supuesto por el que un trabajador desplazado para realizar un trabajo en otro Estado miembro sigue sujeto a la legislación del primer Estado miembro constituye una excepción a la norma general, conforme a la cual la persona que ejerce una actividad por cuenta ajena o propia en un Estado miembro está sujeta a la legislación de ese Estado miembro. Esta excepción no puede aplicarse a una empresa de trabajo temporal que, en el Estado miembro en el que está establecida, no lleve a cabo en absoluto - o, a lo sumo, lo haga de manera no significativa - la cesión de trabajadores a empresas usuarias que también estén establecidas en el referido Estado miembro.

Por último, en cuanto al objetivo perseguido por la disposición analizada, el Tribunal de Justicia afirmó que la excepción contenida en el art. 12, apdo. 1, del Reglamento n. ${ }^{\circ} 883 / 2004$, que representa una ventaja dispensada a las empresas que hacen uso de la libre prestación de servicios, no puede beneficiar a las empresas de trabajo temporal que orientan su actividad de cesión de trabajadores, en exclusiva o principalmente, hacia uno o varios Estados miembros distintos de aquel en el que ellas mismas están establecidas. En efecto, la solución contraria podría incitar a estas empresas al llamado forum shopping, estableciéndose en el Estado miembro que tenga la legislación de seguridad social que les resulte más favorable.

Los ciudadanos de la Unión que no ejercen una actividad económica, residentes en un Estado miembro diferente de su Estado miembro de origen, tienen derecho a quedar afiliados al sistema público de seguro de enfermedad del Estado miembro de acogida; no obstante, la obligación de afiliación a dicho sistema no tiene que ser necesariamente gratuita (Sentencia de 15 de julio de 2021, A, C-535/19, EU:C:2021:595). 
En esta sentencia, el Tribunal de Justicia confirmó el derecho de los ciudadanos de la Unión que no ejercen una actividad económica, residentes en un Estado miembro diferente del de su origen, a quedar afiliados al sistema público de seguro de enfermedad del Estado miembro de acogida, para disfrutar de prestaciones de atención médica financiadas por dicho Estado.

$\mathrm{El}$ asunto ante los tribunales nacionales concernía a un nacional italiano que se instaló en Letonia con el fin de reunirse con su esposa, de nacionalidad letona, y sus dos hijos menores de edad. En Letonia solicitó su inscripción en el sistema público de seguro de enfermedad obligatorio letón. Su solicitud fue denegada debido a que A no estaba comprendido en ninguna de las categorías de beneficiarios de la atención médica financiada por el Estado pues no era trabajador por cuenta ajena ni por cuenta propia en Letonia. El Sr. A recurrió esta decisión en los tribunales nacionales. En este contexto, el Tribunal Supremo de Letonia, ante el que A interpuso un recurso de casación, solicitó al Tribunal de Justicia que se pronunciara acerca de la compatibilidad de la desestimación por las autoridades letonas de la solicitud formulada por A con el derecho de la Unión en los ámbitos de la ciudadanía y de la seguridad social.

El Tribunal de Justicia declaró, en primer lugar, que las prestaciones financiadas por el Estado que se conceden a las personas comprendidas en las categorías de beneficiarios definidas por la legislación nacional al margen de cualquier apreciación individual y discrecional de las necesidades personales constituyen prestaciones de enfermedad en el sentido del art. 3, apdo. 1, letra a), del Reglamento n. ${ }^{\circ} 883 / 2004$.

Seguidamente, el Tribunal de Justicia indicó, que, en el marco del sistema de normas de conflicto establecido por el Reglamento n. ${ }^{\circ}$ 883/2004, para determinar la legislación nacional aplicable a la percepción de las prestaciones de seguridad social, las personas que no ejercen actividades económicas están sujetas, en principio, a la legislación del Estado miembro de su residencia. Estableció, además, que, dado que las normas de conflicto que establece el Reglamento n. ${ }^{\circ} 883 / 2004$ se imponen con carácter imperativo a los Estados miembros, éstos no disponen de la facultad de determinar en qué medida es aplicable su propia legislación o la de otro Estado miembro. Por consiguiente, un Estado miembro no puede, en virtud de su legislación nacional, negarse a afiliar a su sistema público de seguro de enfermedad a un ciudadano de la Unión que está sujeto a la legislación de ese Estado miembro.

A continuación, el Tribunal de Justicia analizó la incidencia sobre la afiliación a la seguridad social del Estado miembro de acogida de las disposiciones de la Directiva 2004/38, y en particular de su art. 7, apdo. 1, letra b). De esta disposición se desprende que, durante todo el período de residencia en el territorio del Estado miembro de acogida superior a tres meses e inferior 
a cinco años, aquellos ciudadanos de la Unión que no ejerzan una actividad económica deben, entre otras cosas, disponer, para sí mismos y para los miembros de sus familias, de un seguro de enfermedad que cubra todos los riesgos para no convertirse en una carga excesiva para el erario público de dicho Estado miembro. Así, el Tribunal de Justicia considera que el Estado miembro de acogida puede supeditar la afiliación a su sistema público de seguro de enfermedad de un ciudadano de la Unión que no ejerce una actividad económica y que reside en su territorio a requisitos tales como la celebración o el mantenimiento, por parte de ese ciudadano, de un seguro de enfermedad privado que cubra todos los riesgos, que permita reembolsar a dicho Estado miembro los gastos sanitarios en que haya incurrido por cuenta de ese ciudadano, o el pago, por este último, de una contribución al sistema público de seguro de enfermedad de ese Estado miembro. En este contexto, corresponde, no obstante, al Estado miembro de acogida velar por el respeto del principio de proporcionalidad y, en consecuencia, de modo que no sea excesivamente difícil para ese ciudadano cumplir tales requisitos.

\section{DERECHO SOCIAL}

El Tribunal de Justicia precisa que la Directiva relativa a determinados aspectos de la ordenación del tiempo de trabajo no se opone a que un período de guardia durante el cual un militar esté obligado a permanecer en el cuartel al que está destinado, sin realizar un trabajo efectivo, sea retribuido de manera diferente que un período de guardia durante el cual realiza prestaciones de trabajo efectivo (Sentencia de 15 de julio de 2021, Republika Slovenija (Ministrstvo za obrambo), C-742/19, EU:C:2021:597).

Desde febrero de 2014 hasta julio de 2015, B. K., suboficial del ejército esloveno, prestó un «servicio de imaginaria» ininterrumpido de siete días al mes. Durante dicho servicio, que comprendía períodos durante los cuales debía ejercer una actividad de vigilancia efectiva y períodos durante los cuales solo estaba obligado a permanecer a disposición de sus superiores, B. $K$. estaba localizable y presente permanentemente en el cuartel al que estaba destinado. Al considerar que, por cada uno de esos días de «servicio de imaginaria», solo ocho horas representaban tiempo de trabajo, el Ministerio de Defensa abonó a B. K. el salario normal correspondiente a esas horas y, por las demás horas, le concedió únicamente un complemento por guardia localizada del $20 \%$ del salario base. 
El recurso interpuesto por B. K. con objeto de que se le pagaran, como horas extraordinarias de trabajo, las horas durante las cuales, en el «servicio de imaginaria», no había ejercido ninguna actividad efectiva al servicio de su empleador, pero había tenido la obligación de permanecer a disposición de sus superiores, fue desestimado en primera instancia y en apelación. En este contexto, el Tribunal Supremo de Eslovenia, decidió preguntar al Tribunal de Justicia sobre la aplicabilidad a la actividad de imaginaria realizada por un militar en tiempo de paz de la Directiva 2003/88/CE del Parlamento Europeo y del Consejo, relativa a determinados aspectos de la ordenación del tiempo de trabajo, que establece disposiciones mínimas relativas, en particular, a la duración del tiempo de trabajo, y, en su caso, sobre si el período de guardia durante el cual el militar tiene obligación de permanecer en el cuartel al que está destinado, sin realizar una actividad laboral efectiva, debe ser considerado tiempo de trabajo, en el sentido del art. 2 de dicha directiva, a los efectos de la fijación de la retribución adeudada a dicho militar por ese período.

En su sentencia el Tribunal de Justicia precisa, en primer lugar, los casos en los que la actividad de imaginaria ejercida por un militar está excluida del ámbito de aplicación de la Directiva 2003/88. Para ello, el Tribunal de Justicia observa, en primer lugar, que el art. 4 TUE, apdo. 2, que establece que la seguridad nacional será responsabilidad exclusiva de cada Estado miembro, no tiene por efecto excluir del ámbito de aplicación del derecho de la Unión la ordenación del tiempo de trabajo de los militares. A tenor de esa misma disposición, la Unión respetará las funciones esenciales del Estado, especialmente las que tienen por objeto garantizar su integridad territorial, mantener el orden público y salvaguardar la seguridad nacional. A este respecto, el Tribunal de Justicia señala que las funciones principales de las fuerzas armadas de los Estados miembros, que son la preservación de la integridad territorial y la salvaguardia de la seguridad nacional, figuran expresamente entre las funciones esenciales del Estado que la Unión debe respetar. Precisa que de ello no se desprende, sin embargo, que las decisiones de los Estados miembros relativas a la organización de sus fuerzas armadas queden fuera del ámbito de aplicación del derecho de la Unión, en particular cuando se trata de normas armonizadas relativas a la ordenación del tiempo de trabajo.

Si bien el respeto debido por la Unión a las funciones esenciales del Estado no implica, por tanto, excluir íntegramente la ordenación del tiempo de trabajo de los militares del ámbito de aplicación del derecho de la Unión, el art. 4 TUE, apdo. 2, exige que la aplicación a los militares de las normas del derecho de la Unión relativas a dicha adecuación no pueda obstaculizar el buen cumplimiento de estas funciones esenciales. Así pues, el derecho de la Unión debe tomar en consideración las características específicas que cada 
Estado miembro atribuye al funcionamiento de sus fuerzas armadas, que resultan, en particular, de las responsabilidades internacionales particulares asumidas por dicho Estado miembro, de los conflictos o de las amenazas a las que se enfrenta, o del contexto geopolítico en el que dicho Estado actúa.

A continuación, por lo que respecta al ámbito de aplicación personal de la Directiva 2003/88, el Tribunal de Justicia recuerda que el concepto de «trabajador» se define en relación con la característica esencial de la relación laboral, a saber, la circunstancia de que una persona realice, en favor de otra y bajo la dirección de esta, determinadas prestaciones a cambio de las cuales percibe una retribución. $\mathrm{Al}$ ser este, durante el período de que se trata, el caso de B. K., dicha directiva es aplicable a su situación.

Por último, por lo que respecta al ámbito de aplicación material de la Directiva 2003/88, definido por remisión al art. 2 de la Directiva 89/391/CEE del Consejo, relativa a la aplicación de medidas para promover la mejora de la seguridad y de la salud de los trabajadores en el trabajo, el Tribunal de Justicia recuerda que esta se aplica a «todos los sectores de actividades, públicas o privadas» (art. 2, apdo. 1) salvo cuando se opongan a ello de manera concluyente las particularidades inherentes a determinadas actividades específicas de la función pública, en particular, en las fuerzas armadas (art. 2, apdo. 2, párr. primero). A este respecto, el Tribunal de Justicia señala que el art. 2 de la Directiva 89/391 no puede interpretarse en el sentido de que los miembros de las fuerzas armadas de los Estados miembros queden fuera, en su totalidad y con carácter permanente, del ámbito de aplicación de la Directiva 2003/88. En efecto, dicha exclusión se refiere no a determinados sectores de la función pública, globalmente considerados, sino solo a determinadas categorías de actividades de dichos sectores, debido a su naturaleza específica. Por lo que respecta, específicamente, a las actividades ejercidas por los militares, el Tribunal de Justicia señala, en particular, que las relacionadas con servicios de administración, mantenimiento, reparación, sanidad, mantenimiento del orden o enjuiciamiento de infracciones no presentan, como tales, particularidades que se opongan a cualquier planificación del tiempo de trabajo que respete las exigencias impuestas por la Directiva 2003/88, al menos mientras dichas actividades no se ejerzan en el marco de una operación militar o durante su preparación inmediata.

En cambio, el Tribunal de Justicia declara que dicha directiva no se aplica a las actividades de los militares y, en particular, a sus actividades de imaginaria, cuando se realizan en el marco de su formación inicial, de un entrenamiento operativo o en el marco de operaciones que presuponen una intervención militar de las fuerzas armadas, tanto si estas se despliegan, permanente u ocasionalmente, dentro de las fronteras del Estado miembro de que se trate, como si lo hacen fuera de ellas. Por otra parte, la Directiva 2003/88 tampoco 
es de aplicación a las actividades militares que son tan específicas que no se prestan a un sistema de rotación de efectivos que permita garantizar el respeto de lo preceptuado por dicha directiva. Lo mismo sucede cuando resulta que la actividad militar se ejecuta en el marco de acontecimientos excepcionales, cuya gravedad y amplitud requieren la adopción de medidas indispensables para la protección de la vida, la salud y la seguridad de la colectividad y cuyo correcto cumplimiento se vería comprometido si debieran respetarse todas las normas establecidas por dicha directiva, o cuando la aplicación de dicha directiva a tal actividad, al obligar a las autoridades afectadas a establecer un sistema de rotación o de planificación del tiempo de trabajo, solo podría hacerse en detrimento del buen cumplimiento de las operaciones militares propiamente dichas. Corresponde al órgano jurisdiccional remitente determinar si la actividad de imaginaria realizada por B. K. encaja en alguno de estos supuestos. En caso de respuesta negativa, esta actividad deberá considerarse comprendida en el ámbito de aplicación de la Directiva 2003/88.

En segundo lugar, el Tribunal de Justicia señala que, aun suponiendo que la Directiva 2003/88 se aplique al caso de autos, un período de guardia impuesto a un militar que suponga su presencia continuada en su lugar de trabajo debe considerarse tiempo de trabajo cuando dicho lugar de trabajo no coincide con su domicilio. Sin embargo, como la forma de retribución de los trabajadores por los períodos de guardia que efectúan se rige por el derecho nacional y no por la Directiva 2003/88, esta última no se opone a que un período de guardia durante el cual un militar esté obligado a permanecer en el cuartel al que está destinado, sin realizar un trabajo efectivo, sea retribuido de forma distinta que un período de guardia durante el cual realiza prestaciones de trabajo efectivo.

La prohibición de llevar cualquier forma visible de expresión de convicciones políticas, filosóficas o religiosas en el lugar de trabajo puede estar justificada por la necesidad del empresario de presentarse de manera neutra ante los clientes o de prevenir conflictos sociales, pero esta justificación debe responder a una verdadera necesidad del empresario y, en el marco de la conciliación de los derechos e intereses en juego, los órganos jurisdiccionales nacionales pueden tener en cuenta el contexto propio de su Estado miembro y, en particular, disposiciones nacionales más favorables para la protección de la libertad religiosa (Sentencia de 15 de julio de 2021, WABE, C804/18 y C341/19, EU:C:2021:594).

IX y MJ, empleadas, respectivamente, como asistente de personas con discapacidad y como vendedora y cajera en sendas sociedades alemanas, llevaban un pañuelo islámico en sus respectivos lugares de trabajo. Conside- 
rando que el hecho de llevar ese pañuelo no respondía al régimen de neutralidad política, filosófica y religiosa seguido ante los padres, los niños y terceros, WABE eV, empleador de IX, pidió a esta que se quitase el pañuelo y, tras la negativa de esta a hacerlo, la suspendió provisionalmente de sus funciones y amonestó en dos ocasiones. MH Müller Handels GmbH, empleador de MJ, ante la negativa de esta de quitarse el pañuelo en su lugar de trabajo, la destinó primero a otro puesto de trabajo que permitía a MJ llevar dicho pañuelo y, posteriormente, tras haberla enviado a casa, le ordenó que se presentase en el lugar de trabajo sin signos de convicciones políticas, filosóficas o religiosas que fueran vistosos y de gran tamaño.

Ambas interpusieron recursos, respectivamente con objeto de que se condenara a WABE a retirar del expediente personal de IX las amonestaciones relativas al uso del pañuelo islámico, y con objeto de que se declarara la nulidad de la orden de $\mathrm{MH}$ y de que se le concediera una indemnización por el perjuicio sufrido. En este contexto, los dos tribunales remitentes decidieron consultar al Tribunal de Justicia sobre la interpretación de la Directiva 2000/78/CE del Consejo, relativa al establecimiento de un marco general para la igualdad de trato en el empleo y la ocupación.

En primer lugar, el Tribunal de Justicia examinó, en relación con el asunto C-804/18, si una norma interna de una empresa que prohíbe a los trabajadores llevar cualquier signo visible de convicciones políticas, filosóficas o religiosas en el lugar de trabajo constituye una discriminación directa por motivos de religión o convicciones, prohibida por los arts. 1 y 2, apdo. 2, letra a), la Directiva 2000/78, de los trabajadores que siguen determinadas reglas vestimentarias con arreglo a preceptos religiosos.

A este respecto, el Tribunal de Justicia indicó que el uso de signos o prendas de vestir para manifestar la religión o las convicciones personales está cubierto por la «libertad de pensamiento, de conciencia y de religión», protegida por el art. 10 de la Carta de los Derechos Fundamentales de la Unión Europea. Además, a efectos de la aplicación de la Directiva 2000/78, los términos «religión» y "convicciones» se consideran las dos caras de un mismo y único motivo de discriminación.

Por otra parte, el Tribunal de Justicia recordó su jurisprudencia según la cual tal norma no constituye una discriminación directa si atañe indistintamente a cualquier manifestación de esas convicciones y trata por igual a todos los trabajadores de la empresa, imponiéndoles, de forma general e indiferenciada, una neutralidad indumentaria que se opone al uso de tales signos. El Tribunal de Justicia consideró que esta apreciación no queda desvirtuada por el hecho de que algunos trabajadores sigan preceptos religiosos que los obligan a vestirse de un determinado modo. Y ello es así porque, si bien una norma como la mencionada puede ocasionar sin duda una particular 
molestia a ese tipo de trabajadores, esta circunstancia no afecta a la apreciación de que esa misma norma, que refleja el régimen de neutralidad de la empresa, no establece, en principio, una diferencia de trato entre trabajadores basada en un criterio indisociablemente ligado a la religión o a las convicciones.

En el asunto objeto de esta sentencia, la norma controvertida parece haberse aplicado de forma general e indiferenciada, habida cuenta de que el empresario de que se trata había exigido y logrado que una empleada que llevaba una cadena con una cruz religiosa accediese a quitarse este signo. El Tribunal de Justicia concluyó pues que, en estas circunstancias, una norma como la controvertida en el litigio principal no constituye una discriminación directa por motivos de religión o convicciones de los trabajadores que siguen determinadas reglas vestimentarias con arreglo a preceptos religiosos.

En segundo lugar, el Tribunal de Justicia examinó si una diferencia de trato basada indirectamente en la religión o las convicciones, en el sentido del art. 2, apdo. 2, letra b), de la Directiva 2000/78, puede estar justificada por la voluntad del empresario de seguir un régimen de neutralidad política, filosófica y religiosa ante sus clientes o usuarios con el fin de tener en cuenta expectativas legítimas de estos. El Tribunal de Justicia respondió afirmativamente a este interrogante tras identificar los elementos que condicionan esta conclusión.

A este respecto, el Tribunal de Justicia comenzó indicando que la voluntad de un empresario de seguir un régimen de neutralidad política, filosófica o religiosa en las relaciones con sus clientes puede constituir una finalidad legítima. El Tribunal de Justicia precisó que, sin embargo, la mera voluntad no es suficiente, por sí sola, para justificar objetivamente una diferencia de trato basada indirectamente en la religión o las convicciones, ya que el carácter objetivo de tal justificación solo puede determinarse ante una "verdadera necesidad» del empresario. Los aspectos pertinentes para determinar esa necesidad son, especialmente, los derechos y las expectativas legítimas de los clientes o de los usuarios y, más específicamente, en materia de enseñanza, el deseo de los padres de que sus hijos sean supervisados por personas que no manifiesten su religión o sus convicciones cuando estén en contacto con los niños.

Para apreciar la existencia de dicha necesidad, resulta especialmente pertinente el hecho de que el empresario aporte la prueba de que, sin el régimen de neutralidad, se vulneraría su libertad de empresa (reconocida en el art. 16 de la Carta), en la medida en que, habida cuenta de la naturaleza de sus actividades o del contexto en el que estas se inscriben, sufriría consecuencias desfavorables.

A continuación, el Tribunal de Justicia puntualizó que la diferencia de trato debe ser apta para garantizar la correcta aplicación del régimen de 
neutralidad, lo que implica que dicho régimen se siga de forma congruente y sistemática. Por último, la prohibición de llevar cualquier signo visible de convicciones políticas, filosóficas y religiosas en el lugar de trabajo ha de limitarse a lo estrictamente necesario en consideración a la amplitud y la gravedad reales de las consecuencias desfavorables que el empresario pretende evitar mediante tal prohibición.

En tercer lugar, el Tribunal de Justicia examinó, en relación con el asunto C-341/19, si una discriminación indirecta basada en la religión o las convicciones, dimanante de una norma interna de una empresa que prohíbe llevar signos visibles de convicciones políticas, filosóficas o religiosas en el lugar de trabajo con el objetivo de garantizar un régimen de neutralidad en el seno de dicha empresa, solo puede justificarse si esa prohibición cubre toda forma visible de expresión de esas convicciones o si es suficiente que dicha prohibición se limite a los signos vistosos y de gran tamaño siempre que se aplique de forma congruente y sistemática.

A este respecto, el Tribunal de Justicia subrayó que esta prohibición limitada puede afectar en mayor medida a los seguidores de aquellas corrientes religiosas, filosóficas y no confesionales que establezcan el uso de una prenda de vestir o de un signo de gran tamaño, como un cubrecabeza. Así pues, cuando el criterio del uso de signos de dichas convicciones que sean vistosos y de gran tamaño esté indisociablemente ligado a una o a varias religiones o convicciones determinadas, la prohibición de llevar esos signos impuesta sobre la base de tal criterio tendrá como consecuencia que determinados trabajadores sean tratados de manera menos favorable que otros por motivo de su religión o de sus convicciones, lo que equivale a una discriminación directa, que no puede justificarse.

En el supuesto de que no se aprecie tal discriminación directa, el Tribunal de Justicia indicó que una diferencia de trato como la controvertida en el litigio principal, si conduce a una desventaja particular para quienes profesan una religión o tienen convicciones determinadas, constituirá una discriminación indirecta, que solo puede justificarse si la prohibición cubre toda forma visible de expresión de las convicciones políticas, filosóficas o religiosas. A este respecto, el Tribunal de Justicia recordó que un régimen de neutralidad en la empresa puede constituir una finalidad legítima y que, para justificar objetivamente una diferencia de trato basada indirectamente en la religión o las convicciones, debe responder a una verdadera necesidad de la empresa, como la prevención de conflictos sociales o la presentación del empresario de manera neutra frente a los clientes. Pues bien, para que pueda seguirse eficazmente tal régimen de neutralidad, no cabe admitir ninguna manifestación visible de convicciones políticas, filosóficas o religiosas cuando los trabajadores estén en contacto con los clientes o cuando estén en contacto entre 
ellos, puesto que el hecho de llevar cualquier signo, incluso pequeño, pone en peligro la aptitud de la norma para alcanzar la finalidad perseguida.

En último lugar, el Tribunal de Justicia declaró que las disposiciones nacionales que protegen la libertad religiosa pueden tenerse en cuenta como disposiciones más favorables al examinar el carácter adecuado de una diferencia de trato basada indirectamente en la religión o las convicciones. El art. 8, apdo. 1, de la Directiva 2000/78, tiene por objeto las disposiciones más favorables para la protección del principio de igualdad de trato que las establecidas en la directiva. Este sería el caso, por ejemplo, de disposiciones nacionales que supediten la justificación de una diferencia de trato basada indirectamente en la religión o las convicciones a requisitos más estrictos que el art. 2, apdo. 2, letra b), inciso i), de dicha Directiva.

A este respecto, el Tribunal de Justicia recordó primero que, al examinar el carácter adecuado, a efectos del art. 2, apdo. 2, letra b), inciso i), de la Directiva 2000/78, de la restricción resultante de una medida destinada a garantizar la aplicación de un régimen de neutralidad política, filosófica y religiosa, deben tenerse en cuenta los diferentes derechos y libertades de que se trate y que corresponde a los órganos jurisdiccionales nacionales, a la luz de todos los elementos de los autos en cuestión, sopesar los intereses presentes y limitar las restricciones de las libertades de que se trate a lo estrictamente necesario. Esto permite asegurar que, cuando estén en juego varios derechos fundamentales y principios consagrados por los Tratados, la valoración de la observancia del principio de proporcionalidad se lleve a cabo respetando la necesaria conciliación de las exigencias relacionadas con la protección de los distintos derechos y principios de que se trate y el justo equilibrio entre ellos. Seguidamente, el Tribunal de Justicia señaló que el legislador de la Unión, al no haber proceder él mismo en la Directiva 2000/78 a la necesaria conciliación entre la libertad de pensamiento, de convicción y de religión y las finalidades legítimas que pueden invocarse como justificación de una desigualdad de trato y al haber dejado el cometido de realizar esta conciliación en manos de los Estados miembros y sus órganos jurisdiccionales, ha permitido tener en cuenta el contexto propio de cada Estado miembro y reconocer a cada uno de ellos un margen de apreciación en el marco de dicha conciliación.

\section{DERECHO DE LA ENERGÍA}

El Tribunal de Justicia desestima el recurso de casación interpuesto por Alemania contra la sentencia del Tribunal General que, con arreglo al principio de solidaridad energética, había anulado una decisión de la Comisión de 2016 por la que se habían modificado las condiciones 
de acceso al gasoducto OPAL, pues la legalidad de cualquier acto de las instituciones de la Unión que forme parte de la política de esta en el ámbito de la energía debe apreciarse a la luz de dicho principio (Sentencia de 15 de julio de 2021, Alemania/Polonia, C848/19 P, EU:C:2021:598).

La línea de conexión del gasoducto del mar Báltico («gasoducto OPAL») es la sección terrestre, al oeste, del gasoducto Nord Stream 1, que transporta gas procedente de Rusia a Europa eludiendo los países de tránsito «tradicionales», como Ucrania, Polonia y Eslovaquia. En 2009, la Comisión Europea había aprobado, con ciertas condiciones, la decisión de la Agencia Federal de Redes alemana de eximir al gasoducto OPAL de las normas de la Directiva 2003/55/CE del Parlamento Europeo y del Consejo, sobre normas comunes para el mercado interior del gas natural (posteriormente sustituida por la Directiva 2009/73/CE del Parlamento Europeo y del Consejo, sobre normas comunes para el mercado interior del gas natural) relativas al acceso de terceros a las redes de gasoductos (art. 18 de la Directiva 2003/55 y art. 32 de la Directiva 2009/73) y a la normativa sobre tarifas (art. 25, apdos. 2 a 4, de la Directiva 2003/55). Dado que Gazprom, empresa dominante en el mercado de suministro de gas, nunca cumplió una de las condiciones impuestas por la Comisión, solo pudo explotar el gasoducto OPAL hasta el $50 \%$ de su capacidad, desde su entrada en servicio en 2011.

En 2016, a petición, en particular, de Gazprom, la Agencia Federal de Redes alemana notificó a la Comisión su intención de modificar determinadas disposiciones de la exención concedida en 2009. En esencia, la modificación prevista debía permitir explotar el gasoducto OPAL en su plena capacidad, a condición de que se vendiera al menos el $50 \%$ de dicha capacidad mediante procedimientos de subasta. La Comisión aprobó dicha modificación con sujeción a determinadas condiciones. Al considerar que la decisión controvertida amenazaba la seguridad del suministro de gas de Polonia, debido a la transferencia a la vía de tránsito Nord Stream 1/OPAL de una parte de los volúmenes de gas natural que hasta entonces transitaban por los Estados de la región de Europa central, entre ellos Polonia, a través de los gasoductos competidores de OPAL, Polonia interpuso un recurso de anulación contra dicha decisión ante el Tribunal General. El Tribunal General estimó el recurso y anuló la Decisión controvertida por considerar que vulneraba el principio de solidaridad energética, consagrado en el art. 194 TFUE, apdo. 1 (T-883/16, EU:T:2019:567). Según el Tribunal General, la Comisión debería haber analizado las repercusiones de la modificación del régimen de explotación del gasoducto OPAL sobre la seguridad del suministro y la política energética de Polonia. 
El Tribunal de Justicia recuerda, en primer lugar, que, según el art. 194 TFUE, apdo. 1, la política energética de la Unión tendrá por objetivo, con un espíritu de solidaridad entre los Estados miembros, asegurar el funcionamiento del mercado de la energía, garantizar la seguridad del abastecimiento energético en la Unión, fomentar la eficiencia energética y el ahorro energético, así como el desarrollo de energías nuevas y renovables, y fomentar la interconexión de las redes energéticas.

A este respecto, el Tribunal de Justicia señala que el principio de solidaridad es un principio fundamental del derecho de la Unión, mencionado en varias disposiciones de los Tratados UE y FUE, que encuentra su expresión concreta, en el ámbito de la energía, en el art. 194 TFUE, apdo. 1. Dado que el principio de solidaridad subyace al conjunto de los objetivos de la política energética de la Unión, nada permite excluir que dicho principio produzca efectos jurídicos vinculantes. Por el contrario, el principio de solidaridad conlleva derechos y obligaciones tanto para la Unión como para los Estados miembros, de manera que la Unión está sujeta a una obligación de solidaridad frente a los Estados miembros y estos están sujetos a la misma obligación entre ellos y con respecto al interés común de la Unión.

El Tribunal de Justicia deduce de ello que la legalidad de cualquier acto de las instituciones de la Unión que forme parte de su política en el ámbito de la energía debe apreciarse a la luz del principio de solidaridad energética, incluso a falta de una referencia expresa a este principio en el Derecho derivado aplicable, a saber, en el caso de autos, la Directiva 2009/73. Por consiguiente, de una lectura conjunta de los principios de solidaridad energética y de cooperación leal se desprende que, al adoptar una decisión por la que se modifica un régimen excepcional, con arreglo al art. 36 de la Directiva 2009/73, la Comisión está obligada a examinar los posibles riesgos para el suministro de gas en los mercados de los Estados miembros.

En segundo lugar, el Tribunal de Justicia indica que el tenor del art. 194 TFUE no restringe la aplicación del principio de solidaridad energética a las situaciones de ataques terroristas o de catástrofes naturales o de origen humano, contempladas en el art. 222 TFUE. Por el contrario, el espíritu de solidaridad mencionado en el art. 194 TFUE, apdo. 1, se extiende a cualquier acción relacionada con la política de la Unión en el ámbito de la energía. Así pues, el deber de las instituciones de la Unión y de los Estados miembros de tener en cuenta el principio de solidaridad energética al adoptar actos relativos al mercado interior del gas natural, velando en particular por garantizar la seguridad del suministro energético de la Unión, se traduce en la adopción tanto de medidas para hacer frente a situaciones de emergencia como de medidas preventivas. La Unión y los Estados miembros deben, al ejercer sus 
respectivas competencias en este ámbito, llevar a cabo una ponderación de los intereses energéticos en juego, evitando adoptar medidas que puedan afectar a los intereses de los actores susceptibles de verse afectados, en relación con la seguridad del suministro, la viabilidad económica y política y la diversificación de las fuentes de suministro, a fin de asumir su interdependencia y solidaridad de hecho.

\section{APROXIMACIÓN DE LEGISLACIONES}

El registro sistemático de direcciones IP de usuarios y la comunicación de sus nombres y direcciones postales al titular de los derechos intelectuales o a un tercero para permitir la presentación de una demanda de indemnización es admisible bajo determinadas condiciones (Sentencia de 17 de junio de 2021, Mircom International/Telenet, C-597/19, EU:C:2021:492).

La empresa Mircom International Content Management \& Consulting (M.I.C.M.) Limited presentó una demanda de información dirigida contra Telenet BVBA, un proveedor de acceso a Internet, ante el Tribunal de Empresas de Amberes (Bélgica). Esta demanda tenía por objeto obtener una resolución que obligara a Telenet a proporcionar los datos de identificación de sus clientes basándose en las direcciones IP recopiladas, por cuenta de Mircom, por una sociedad especializada. Las conexiones a Internet de ciertos clientes de Telenet se habían utilizado para compartir, a través de una red entre pares (peer-to-peer) y por medio del protocolo BitTorrent, películas incluidas en el catálogo de Mircom.

En su sentencia, el Tribunal de Justicia declaró, en primer lugar, que la carga de partes de un archivo multimedia a través de una red entre pares (peer-to-peer), como la que tuvo lugar en el caso de autos, constituye una puesta a disposición del público en el sentido del art. 3, apdos. 1 y 2, de la Directiva 2001/29/CE del Parlamento Europeo y del Consejo, relativa a la armonización de determinados aspectos de los derechos de autor y derechos afines a los derechos de autor en la sociedad de la información. La carga, mediante el uso una red entre pares (peer-to-peer), de partes previamente descargadas de un archivo multimedia que contiene una obra protegida constituye una "puesta a disposición del público», aun a pesar de que esas partes no puedan utilizarse por sí solas y de que la carga tenga lugar de modo automático una vez que el usuario decide utilizar ese software y da su consentimiento a su ejecución tras haber sido debidamente informado sobre sus características. 
Precisa que cualquier usuario de dicha red puede reconstituir fácilmente el archivo original a partir de partes disponibles en los ordenadores del resto de usuarios. Pues bien, al descargar las partes de un archivo, las pone simultáneamente a disposición de otros usuarios para que estos las carguen. A este respecto, el Tribunal de Justicia observó que el usuario no debe descargar efectivamente un número de partes que suponga un umbral mínimo y que cualquier acto mediante el cual dé acceso, con pleno conocimiento de las consecuencias de su comportamiento, a obras protegidas puede constituir un acto de puesta a disposición. En el caso de autos, tuvo efectivamente lugar un acto de esa naturaleza al dirigirse a un número indeterminado de destinatarios potenciales, implicar a un número considerable de personas y efectuarse ante un público nuevo. Esta interpretación pretende mantener el justo equilibrio entre los intereses y los derechos fundamentales de los titulares de los derechos de propiedad intelectual, por una parte, y de los usuarios de prestaciones protegidas, por otra.

En segundo lugar, el Tribunal declara que un titular derechos de propiedad intelectual como Mircom puede acogerse al sistema de protección de dichos derechos, pero su petición de información, en particular, ha de ser no abusiva, justificada y proporcionada, de conformidad con los arts. 3, apdo. 2, y 8 de la Directiva 2004/48/CE del Parlamento Europeo y del Consejo, relativa al respeto de los derechos de propiedad intelectual. El Tribunal de Justicia precisó que la posible constatación de tal abuso entra dentro del ámbito de la apreciación del tribunal remitente, quien, a tal efecto, podría comprobar, por ejemplo, si realmente se han interpuesto acciones judiciales en caso de rechazarse la solución amistosa. Por lo que respecta, en particular, a una petición de información como la que formula Mircom, el Tribunal de Justicia declaró que no puede considerarse inadmisible por el solo hecho de haber sido formulada en una fase anterior al ejercicio de la acción jurisdiccional. No obstante, tal petición debe desestimarse si es injustificada o no proporcionada, extremo que corresponde verificar al tribunal remitente. Mediante esta interpretación, el Tribunal de Justicia pretende garantizar un nivel elevado de protección de la propiedad intelectual en el mercado interior.

En tercer lugar, el Tribunal de Justicia declaró que el derecho de la Unión no se opone, en principio, ni al registro sistemático, por parte del titular de derechos de propiedad intelectual y por parte de un tercero que actúa por cuenta de este, de direcciones IP de usuarios de redes entre pares (peer-to-peer) cuyas conexiones de Internet supuestamente se utilizaron en actividades infractoras contra la propiedad intelectual (tratamiento de datos inicial), ni tampoco a la comunicación de los nombres y de las direcciones postales de esos usuarios al comentado titular o a un tercero para la presentación de una demanda de indemnización (tratamiento de datos efectuado 
en una fase posterior). No obstante, las iniciativas y las pretensiones al efecto han de ser justificadas, proporcionadas y no abusivas y fundamentarse jurídicamente en una medida legal nacional que limite el alcance de los derechos y obligaciones comprendidos en el derecho de la Unión. El Tribunal de Justicia precisó que dicho ordenamiento no impone, a una sociedad como Telenet, la obligación de comunicar a los particulares datos personales para permitir ejercer acciones ante la jurisdicción civil contra las infracciones al derecho de propiedad intelectual. Sin embargo, el derecho de la Unión sí permite a los Estados miembros imponer tal obligación.

Los operadores de plataformas en línea no realizan por sí mismos, en principio, una comunicación al público de los contenidos protegidos por los derechos de autor que los usuarios de tales plataformas ponen ilegalmente en línea, pero esos operadores llevan a cabo tal comunicación vulnerando los derechos de autor si, más allá de la mera puesta a disposición de las plataformas, contribuyen a proporcionar al público acceso a dichos contenidos (Sentencia de 22 de junio de 2021, Peterson/ Google, C-682/18 y C-683/18, EU:C:2021:503).

En el litigio que dio origen al primer asunto (C-682/18), Frank Peterson, un productor musical, demandó a YouTube y a su representante legal Google ante los órganos jurisdiccionales alemanes en relación con la puesta en línea en YouTube, en el año 2008, de varios fonogramas sobre los que alega ser titular de diferentes derechos. Esta puesta en línea fue efectuada por usuarios de la mencionada plataforma sin la autorización del Sr. Frank Peterson.

En el litigio que dio lugar al segundo asunto (C-683/18), la editorial Elsevier demandó a Cyando ante los órganos jurisdiccionales alemanes en relación con la puesta en línea en su plataforma de alojamiento y de intercambio de archivos "Uploaded», en el año 2013, de distintas obras cuyos derechos exclusivos pertenecen a Elsevier. Esta puesta en línea fue efectuada por usuarios de la mencionada plataforma sin que Elsevier lo autorizara.

El Bundesgerichtshof (Tribunal Supremo de lo Civil y Penal, Alemania), que conoce de ambos litigios, planteó varias cuestiones prejudiciales al Tribunal de Justicia con el fin de que este precise, entre otros, la responsabilidad de los operadores de plataformas en línea en relación con las obras protegidas por los derechos de autor que los usuarios de tales plataformas suben a ellas de forma ilícita.

El Tribunal de Justicia examina esta responsabilidad conforme al régimen aplicable en el momento de los hechos, resultante de la Directiva 2001/29/CE del Parlamento Europeo y del Consejo, relativa a la armonización de determinados aspectos de los derechos de autor y derechos afines a los derechos 
de autor en la sociedad de la información, de la Directiva 2000/31/CE del Parlamento Europeo y del Consejo, relativa a determinados aspectos jurídicos de los servicios de la sociedad de la información, en particular del comercio electrónico en el mercado interior (sobre el comercio electrónico), y de la Directiva 2004/48/CE del Parlamento Europeo y del Consejo, relativa al respeto de los derechos de propiedad intelectual. Las cuestiones prejudiciales planteadas no atañen al régimen que entró en vigor con posterioridad al momento de los hechos, establecido por la Directiva (UE) 2019/790 del Parlamento Europeo y del Consejo, sobre los derechos de autor y derechos afines en el mercado único digital.

En primer lugar, el Tribunal de Justicia examina la cuestión de si el operador de una plataforma de intercambio de vídeos o de una plataforma de alojamiento y de intercambio de archivos, en la que los usuarios pueden poner ilegalmente a disposición del público contenidos protegidos, efectúa por sí mismo, en circunstancias como las de los presentes asuntos, una "comunicación al público» de estos contenidos, en el sentido del art. 3, apdo. 1, de la Directiva 2001/29 sobre los derechos de autor. En virtud de esta disposición, los Estados miembros establecerán en favor de los autores el derecho exclusivo a autorizar o prohibir cualquier comunicación al público de sus obras, por procedimientos alámbricos o inalámbricos, incluida la puesta a disposición del público de sus obras de tal forma que cualquier persona pueda acceder a ellas desde el lugar y en el momento que elija.

El Tribunal de Justicia comienza recordando los objetivos y la definición del concepto de "comunicación al público", así como los criterios complementarios que deben tenerse en cuenta en la apreciación individualizada que implica este concepto. De este modo, el Tribunal de Justicia destaca, entre esos criterios, el papel ineludible desempeñado por el operador de la plataforma y el carácter deliberado de su intervención. En efecto, este realiza un «acto de comunicación» cuando interviene, con pleno conocimiento de las consecuencias de su conducta, para proporcionar a sus clientes acceso a una obra protegida, especialmente cuando, si no tuviera lugar tal intervención, los clientes no podrían, en principio, disfrutar de la obra difundida.

En este contexto, el Tribunal de Justicia considera que el operador de una plataforma de intercambio de vídeos o de una plataforma de alojamiento y de intercambio de archivos, en la que los usuarios pueden poner ilegalmente a disposición del público contenidos protegidos, no realiza una «comunicación al público» de estos, en el sentido de la directiva sobre los derechos de autor, a menos que contribuya, más allá de la mera puesta a disposición de la plataforma, a proporcionar al público acceso a tales contenidos vulnerando los derechos de autor. 
Así sucede, en particular, cuando ese operador tiene conocimiento concreto de la puesta a disposición ilícita de un contenido protegido en su plataforma y se abstiene de eliminarlo o de bloquear el acceso a él con prontitud, o cuando dicho operador, pese a que sabe o debería saber que, de manera general, usuarios de su plataforma ponen ilegalmente a disposición del público, por medio de ella, contenidos protegidos, se abstiene de aplicar las medidas técnicas apropiadas que cabe esperar de un operador normalmente diligente en su situación con el fin de combatir de forma creíble y eficaz violaciones de los derechos de autor en esa plataforma, o también cuando participa en la selección de contenidos protegidos y comunicados ilegalmente al público, proporciona en su plataforma herramientas destinadas específicamente al intercambio ilícito de tales contenidos o promueve a sabiendas esos intercambios, de lo que puede ser prueba el hecho de que el operador haya adoptado un modelo económico que incite a los usuarios de su plataforma a proceder ilegalmente, en ella, a la comunicación al público de contenidos protegidos.

En segundo lugar, el Tribunal de Justicia aborda la cuestión de si un operador de plataformas en línea puede beneficiarse de la exención de responsabilidad, prevista por el art. 14, apdo. 1, de la Directiva 2000/31 sobre el comercio electrónico. Según esta disposición, los Estados miembros garantizarán que, cuando se preste un servicio de la sociedad de la información consistente en almacenar datos facilitados por el destinatario del servicio, el prestador de servicios no pueda ser considerado responsable de los datos almacenados a petición del destinatario, a condición de que el prestador de servicios no tenga conocimiento efectivo de que la actividad o la información es ilícita y, en lo que se refiere a una acción por daños y perjuicios, no tenga conocimiento de hechos o circunstancias por los que la actividad o la información revele su carácter ilícito, o de que, en cuanto tenga conocimiento de estos puntos, el prestador de servicios actúe con prontitud para retirar los datos o hacer que el acceso a ellos sea imposible.

En este contexto, el Tribunal de Justicia examina si el papel desempeñado por ese operador es neutro, es decir, si su comportamiento es meramente técnico, automático y pasivo, lo que implica la falta de conocimiento o control de los contenidos que almacena, o si, por el contrario, dicho operador desempeña un papel activo que le permite adquirir conocimiento o control de tales contenidos. A este respecto, el Tribunal de Justicia considera que ese operador puede acogerse a la exención de responsabilidad siempre que no desempeñe un papel activo que pueda conferirle un conocimiento o un control de los contenidos subidos a su plataforma. Sobre este particular, el Tribunal de Justicia precisa que, para que tal operador quede excluido, en virtud de esta disposición, de la exención de responsabilidad 
prevista en la citada directiva, debe tener conocimiento de los actos ilícitos concretos de sus usuarios referentes a contenidos protegidos que han sido subidos a su plataforma.

En tercer lugar, el Tribunal de Justicia precisa los requisitos para que los titulares de los derechos puedan obtener medidas cautelares, contra operadores de plataformas en línea, en virtud del art. 8, apdo. 3, de la Directiva 2001/29 sobre los derechos de autor. Según esta disposición, los Estados miembros velarán por que los titulares de los derechos estén en condiciones de solicitar medidas cautelares contra los intermediarios a cuyos servicios recurra un tercero para infringir un derecho de autor o un derecho afín a los derechos de autor. De este modo, declara que esta directiva no se opone a que, en virtud del derecho nacional, el titular de los derechos de autor o de los derechos afines a los derechos de autor solo pueda obtener medidas cautelares contra el operador cuyo servicio haya sido utilizado por un tercero para vulnerar sus derechos, sin que tal operador haya tenido conocimiento de ello, con arreglo al art. 14, apdo. 1, letra a), de la Directiva 2000/31 sobre el comercio electrónico, cuando, antes del inicio del procedimiento judicial, esa vulneración haya sido previamente notificada a dicho operador sin que este haya intervenido con prontitud para retirar el contenido en cuestión o para bloquear el acceso al citado contenido y para velar por que tales vulneraciones no se reproduzcan.

Sin embargo, corresponde a los órganos jurisdiccionales nacionales asegurarse de que, en su aplicación, este requisito no lleva a que la cesación efectiva de la vulneración se retrase de tal modo que provoque daños desproporcionados a ese titular.

\section{JUSTICIA, LIBERTAD Y SEGURIDAD}

El principio que prohíbe el doble enjuiciamiento puede oponerse a la detención, en el espacio Schengen y en la Unión Europea, de una persona objeto de una notificación de Interpol, cuando las autoridades competentes tienen conocimiento de una resolución judicial firme en la que se declara aplicable dicho principio adoptada en un Estado parte en el Acuerdo de Schengen o un Estado miembro (Sentencia de 12 de mayo de 2021, WS, C-505/19, EU:C:2021:376).

En 2012, la Interpol publicó, a petición de los Estados Unidos y sobre la base de una orden de detención dictada por las autoridades de este país, una notificación roja referida a WS, de nacionalidad alemana, con miras a su eventual extradición. Cuando se localiza en un Estado afiliado a Interpol 
a una persona objeto de una notificación roja, ese Estado debe, en principio, proceder a su detención preventiva o a vigilarla o limitar sus desplazamientos.

No obstante, antes de que se publicase dicha notificación roja, se había incoado contra WS en Alemania un procedimiento de investigación referido, según el órgano jurisdiccional remitente, a los mismos hechos que aquellos en los que se basaba dicha notificación roja. Este procedimiento se archivó con carácter firme en 2010, una vez que WS hubo abonado una determinada cantidad dineraria, acogiéndose a un procedimiento específico de transacción previsto en el derecho penal alemán. Posteriormente, el Bundeskriminalamt (Oficina Federal de Policía Criminal, Alemania) informó a Interpol de que consideraba que, a la vista de ese procedimiento anterior, el principio non bis in idem era aplicable al presente asunto.

En 2017, WS interpuso un recurso contra Alemania ante el Verwaltungsgericht Wiesbaden (Tribunal de lo Contencioso-Administrativo de Wiesbaden, Alemania) con la pretensión de que se ordenara a esta adoptar las medidas necesarias para la retirada de la notificación roja. A este respecto, WS invoca, además de la violación del principio non bis in idem, la violación de su derecho a la libre circulación, garantizado por el art. 21 TFUE, dado que no puede desplazarse a los Estados parte en el Acuerdo de Schengen o a los Estados miembros sin correr el riesgo a ser detenido. Aduce asimismo que, debido a estas violaciones, el tratamiento de sus datos personales consignados en la notificación roja es contrario a la Directiva (UE) 2016/680 del Parlamento Europeo y del Consejo, relativa a la protección de las personas físicas en lo que respecta al tratamiento de datos personales por parte de las autoridades competentes para fines de prevención, investigación, detección o enjuiciamiento de infracciones penales o de ejecución de sanciones penales, y a la libre circulación de dichos datos.

En este contexto, el Tribunal de lo Contencioso-Administrativo de Wiesbaden decidió consultar al Tribunal de Justicia sobre la aplicación del principio non bis in idem y, más concretamente, sobre la posibilidad de que se proceda a la detención preventiva de una persona objeto de una notificación roja en una situación como esta. Además, en caso de que este principio sea aplicable, el órgano jurisdiccional remitente desea que se dilucide qué consecuencias se derivarían para el tratamiento por parte de los Estados miembros de los datos personales consignados en tal notificación.

Con carácter preliminar, el Tribunal de Justicia recuerda que el principio non bis in idem es susceptible de aplicarse en una situación como la controvertida, esto es, en un contexto en el que se ha adoptado una resolución por la que se archiva con carácter firme un proceso penal una vez que la persona objeto del mismo ha cumplido determinadas condiciones, en particular el abono de una cantidad dineraria fijada por el Ministerio Fiscal. Hecha esta 
precisión, el Tribunal de Justicia considera, en primer lugar, que el art. 54 del Convenio de Aplicación del Acuerdo de Schengen («CAAS»), el art. 50 de la Carta y el art. 21 TFUE, apdo. 1, no se oponen a la detención preventiva de una persona objeto de una notificación roja de Interpol mientras no se haya determinado que esta ha sido juzgada en sentencia firme en un Estado parte en el Acuerdo de Schengen o en un Estado miembro por los mismos hechos que aquellos en que se basa la notificación roja y por ende que el principio non bis in idem resulta aplicable.

A este respecto, el Tribunal de Justicia indica que, cuando existe incertidumbre sobre la aplicabilidad del principio non bis in idem, la detención preventiva de una persona puede constituir una actuación indispensable para efectuar las comprobaciones necesarias al tiempo que se evita que se dé a la fuga. En consecuencia, tal medida está justificada en tal caso por el objetivo legítimo de evitar la impunidad de esta persona. En cambio, cuando en una resolución judicial firme se ha declarado aplicable el principio non bis in idem, tanto la confianza mutua existente entre los Estados parte en el Acuerdo de Schengen como el derecho de libre circulación se oponen a tal detención preventiva o al mantenimiento de esta detención. El Tribunal de Justicia precisa que incumbe a los Estados miembros y a los Estados parte en el Acuerdo de Schengen garantizar la existencia de vías de recurso que permitan a las personas en cuestión obtener tal resolución judicial. Señala además que, cuando una detención preventiva sea incompatible con el derecho de la Unión por ser aplicable el principio non bis in idem, un Estado afiliado a Interpol que se abstenga de efectuar tal detención no estaría incumpliendo las obligaciones que le incumben como miembro de esta organización.

En segundo lugar, en lo referente a la cuestión de los datos personales consignados en una notificación roja de Interpol, el Tribunal de Justicia indica que toda operación realizada sobre tales datos, como su registro en los ficheros de búsqueda de un Estado miembro, constituye un «tratamiento» comprendido en los arts. 2, apdo. 1, y 3, punto 2, de la Directiva 2016/680. Estima, además, por un lado, que ese tratamiento persigue un fin legítimo y, por otro, que no puede considerarse ilícito meramente porque el principio non bis in idem pudiera resultar aplicable a los hechos en los que la notificación roja se basa (arts. 4, apdo. 1, letra b), y 8, apdo. 1, de la Directiva 2016/680). Por añadidura, tal tratamiento por parte de las autoridades de los Estados miembros puede resultar indispensable precisamente para comprobar si dicho principio resulta aplicable.

En estas circunstancias, el Tribunal de Justicia declara, asimismo, que la Directiva 2016/680, a la luz del art. 54 del CAAS y del art. 50 de la Carta, no se opone al tratamiento de los datos personales que figuran en una notificación roja mientras no se haya determinado en una resolución judicial firme 
que el principio non bis in idem resulta aplicable al caso. No obstante, tal tratamiento debe respetar los requisitos establecidos en dicha directiva. Desde esta perspectiva, en particular, debe ser necesario para la realización de una tarea efectuada por una autoridad nacional competente para fines de prevención, investigación, detección o enjuiciamiento de infracciones penales o de ejecución de sanciones penales (arts. 1, apdo. 1, y 8, apdo. 1, de la Directiva 2016/680).

En cambio, cuando el principio non bis in idem resulta aplicable, ya no es necesario registrar en los ficheros de búsqueda de los Estados miembros datos personales consignados en una notificación roja de Interpol, puesto que tal persona ya no puede ser objeto de diligencias penales por los hechos a los que se refiere dicha notificación roja y, en consecuencia, ser detenida por esos hechos. De ello se sigue que esa persona debe poder exigir la supresión de sus datos. Si no obstante se mantiene este registro, debe acompañarse de la indicación de que esa persona no puede volver a ser perseguida en un Estado miembro o en un Estado contratante por los mismos hechos, por encontrarse protegida por el principio non bis in idem.

\section{RELACIONES EXTERIORES}

Venezuela está legitimada para impugnar un reglamento que introduce medidas restrictivas en su contra, por lo que el Tribunal de Justicia anula la sentencia del Tribunal General que había declarado lo contrario y le devuelve el asunto para que se pronuncie sobre el fondo del recurso de anulación (Sentencia de 22 de junio de 2021, Venezuela/Consejo, C-872/19 P, EU:C:2021:507).

En vista del deterioro de la situación de los derechos humanos, del Estado de Derecho y de la democracia, el Consejo de la Unión Europea adoptó, en 2017, unas medidas restrictivas contra la República Bolivariana de Venezuela. Los arts. 2, 3, 6 y 7 del Reglamento (UE) 2017/2063 del Consejo, relativo a medidas restrictivas habida cuenta de la situación en Venezuela, establecían, en particular, la prohibición de vender o suministrar a cualquier persona física o jurídica, entidad u organismo en Venezuela equipos militares y las tecnologías relacionadas con ellos que puedan utilizarse para la represión interna, así como la prohibición de prestar a esas mismas personas físicas o jurídicas, entidades u organismos en Venezuela determinados servicios técnicos, de intermediación o financieros relacionados con el suministro de dichos equipos.

Venezuela interpuso un recurso de anulación del Reglamento 2017/2063, en cuanto le afectan sus disposiciones. Posteriormente, adaptó su demanda 
para que tuviera también por objeto la Decisión 2018/1656 y el Reglamento de Ejecución 2018/1653, actos mediante los que el Consejo había prorrogado las medidas restrictivas adoptadas. Mediante sentencia de 20 de septiembre de 2019, el Tribunal General declaró la inadmisibilidad de dicho recurso, debido a que las disposiciones controvertidas no afectaban directamente la situación jurídica de Venezuela (Venezuela/Consejo, T-65/18, EU:T:2019:649). El Tribunal de Justicia anula la sentencia del Tribunal General en la medida en que este había declarado la inadmisibilidad del recurso de Venezuela dirigido a la anulación de los arts. 2, 3, 6 y 7 del Reglamento 2017/2063 y devuelve el asunto al Tribunal General para que resuelva en cuanto al fondo.

Con carácter preliminar, el Tribunal de Justicia señala que, dado que el recurso de casación de Venezuela no se refiere a la parte de la sentencia recurrida en la que se declaró la inadmisibilidad del recurso de ese Estado tercero dirigido a la anulación del Reglamento de Ejecución 2018/1653 y de la Decisión 2018/1656, el Tribunal General se pronunció definitivamente al respecto. A continuación, el Tribunal de Justicia recuerda que, según reiterada jurisprudencia, puede pronunciarse, de oficio si es necesario, sobre un motivo de orden público basado en el incumplimiento de los requisitos de admisibilidad establecidos en el art. 263 TFUE.

En el caso de autos, plantea de oficio la cuestión de si Venezuela puede ser considerada "persona jurídica», a efectos del art. 263 TFUE, párr. cuarto. A este respecto, señala que de esta disposición no se desprende que determinadas categorías de personas jurídicas no puedan invocar la facultad de interponer un recurso de anulación prevista en dicho artículo. Por otra parte, tampoco se desprende de su jurisprudencia anterior que el concepto de "persona jurídica», utilizado en el art. 263 TFUE, párr. cuarto, sea objeto de interpretación restrictiva. Acto seguido, el Tribunal de Justicia subraya que el principio de que la Unión se fundamenta, entre otros, en el valor del Estado de Derecho resulta tanto del art. 2 TUE como del art. 21 TUE, al que remite el art. 23 TUE, relativo a la PESC. En estas circunstancias, declara que, con arreglo al art. 263 TFUE, párr. cuarto, interpretado a la luz de los principios de control judicial efectivo y del Estado de Derecho, un Estado tercero debería tener legitimación procesal, como "persona jurídica», a efectos del art. 263 TFUE, párr. cuarto, cuando concurran los demás requisitos previstos en dicha disposición. Sobre este particular, precisa que las obligaciones de la Unión de velar por el respeto del Estado de Derecho no están supeditadas a un requisito de reciprocidad. Por lo tanto, Venezuela, como Estado dotado de personalidad jurídica internacional, debe considerarse "persona jurídica», a efectos del art. 263 TFUE, párr. cuarto.

A continuación, el Tribunal de Justicia declara que el Tribunal General incurrió en error de derecho al considerar que las medidas restrictivas 
en cuestión no surtían efectos directamente en la situación jurídica de Venezuela. A este respecto, señala que dichas medidas fueron adoptadas contra Venezuela. En efecto, prohibir a los operadores de la Unión efectuar determinadas operaciones equivalía a prohibir a Venezuela efectuar tales operaciones con esos operadores. Por otra parte, dado que la entrada en vigor del Reglamento 2017/2063 tuvo por efecto la aplicación inmediata y automática de las prohibiciones establecidas en sus arts. 2, 3, 6 y 7, esas prohibiciones impedían a Venezuela procurarse numerosos bienes y servicios. El Tribunal de Justicia deduce de ello que estas disposiciones surten efectos directamente en la situación jurídica de dicho Estado. Señala, a este respecto, que no es necesario distinguir en función de si las operaciones comerciales de dicho Estado corresponden a actos de gestión (iure gestionis) o a actos de autoridad pública (iure imperii). Asimismo, señala que el hecho de que las medidas restrictivas en cuestión no constituyan un impedimento absoluto para que Venezuela se procure los bienes y servicios de que se trata es irrelevante a estos efectos.

Posteriormente, el Tribunal de Justicia se pronuncia sobre el fondo de los demás motivos de inadmisibilidad inicialmente invocados por el Consejo ante el Tribunal General. Por lo que respecta al motivo basado en la falta de interés en ejercitar la acción de Venezuela, el Tribunal de Justicia considera que, toda vez que las prohibiciones establecidas en los arts. 2, 3, 6 y 7 del Reglamento 2017/2063 pueden perjudicar los intereses, en particular económicos, de Venezuela, su anulación puede procurarle, por sí misma, un beneficio. En cuanto al motivo basado en que las disposiciones controvertidas no afectan directamente a Venezuela, el Tribunal de Justicia estima que las prohibiciones establecidas en los artículos en cuestión del Reglamento 2017/2063 se aplican sin dejar margen alguno de apreciación a los destinatarios encargados de su aplicación y sin necesidad de adoptar medidas de ejecución. En la medida en que ya había declarado que dichas disposiciones surten efectos en la situación jurídica de Venezuela, el Tribunal de Justicia desestima este motivo.

Por último, el Tribunal de Justicia declara que el Reglamento 2017/2063 constituye un "acto reglamentario», a efectos del art. 263 TFUE, párr. cuarto. Además, dado que los artículos de dicho reglamento impugnados por Venezuela no incluyen medidas de ejecución, el Tribunal de Justicia concluye que este Estado tercero está efectivamente legitimado para impugnarlos sobre la base de la citada disposición, sin tener que demostrar que dichos artículos lo afectan individualmente. 